SYSTEMATIC REVIEW

\title{
Mapping global prevalence of depression among postpartum
}

\section{women}

Ziyi Wang ${ }^{1,11}$, Jiaye $\mathrm{Liu}^{2,11}$, Huan Shuai ${ }^{3,11}$, Zhongxiang Cai ${ }^{4,11}$, Xia Fu ${ }^{5}$, Yang Liu ${ }^{6}$, Xiong Xiao ${ }^{7}$, Wenhao Zhang ${ }^{8}$, Elise Krabbendam ${ }^{9}$, Shuo Liu ${ }^{1}$, Zhongchun Liu (iD ${ }^{10^{凶}}$, Zhihui $\mathrm{Li}^{2^{凶}}$ and Bing Xiang Yang (D)

(c) The Author(s) 2021, corrected publication 2021

Postpartum depression (PPD) is the most common psychological condition following childbirth, and may have a detrimental effect on the social and cognitive health of spouses, infants, and children. The aim of this study was to complete a comprehensive overview of the current literature on the global epidemiology of PPD. A total of 565 studies from 80 different countries or regions were included in the final analysis. Postpartum depression was found in $17.22 \%(95 \% \mathrm{Cl} 16.00-18.51)$ of the world's population. Meta-regression analysis showed that study size, country or region development, and country or region income were the causes of heterogeneity. Multivariable meta-regression analysis found that study size and country or area development were the most important predictors. Varied prevalence rates were noted in geographic regions with the highest rate found in Southern Africa (39.96\%). Of interested was a significantly lower rate of PPD in developed countries or high-income countries or areas. Furthermore, the findings showed that there was a substantial difference in rates of PPD when marital status, educational level, social support, spouse care, violence, gestational age, breast feeding, child mortality, pregnancy plan, financial difficulties, partnership, life stress, smoking, alcohol intake, and living conditions were considered in the pooled estimates. Our results indicated that one out of every five women experiences PPD which is linked to income and geographic development. It is triggered by a variety of causes that necessitate the attention and committed intervention of primary care providers, clinicians, health authorities, and the general population.

Translational Psychiatry (2021)11:543; https://doi.org/10.1038/s41398-021-01663-6

\section{INTRODUCTION}

Postpartum depression (PPD), the onset of depressive episodes after childbirth, develops at a critical moment in a woman's life and can continue for long periods [1, 2]. The likelihood of depressive episodes can be twice as high as during other periods of a woman's life [3], and they often go undetected and untreated [4], wreaking havoc on partners as well as the emotional and cognitive growth of infants and adolescents $[5,6]$. Desperation, sadness, nausea, changes in sleep and eating habits, decreased libido, crying spells, anxiety, irritability, feelings of isolation, mental liability, thoughts of hurting oneself and/or the infant, and even thoughts of suicide are common signs of this form of depression [7]. Postpartum depression can start at any time within the first year after delivery and continue for several years.

In Western countries, the prevalence of PPD varies from 10 to $15 \%$ during the first year after birth [8]. According to a systematic review of 47 studies from 18 low and lower-middle income countries, the prevalence is $18.6 \%$ (95\% Cl 18.0-19.2). Moreover, another review involving 143 studies from 40 countries found a broader variety of PPD prevalence rates, ranging from $0.5 \%$ to around $60 \%$ [9]. Cultural variations, diverse reporting practices, different viewpoints on mental health issues and stigma, socioeconomic class, poverty, poor social services, deficient nutrition, elevated stress, and biological factors can all be related to this broader continuum.

Despite the increasing number of longitudinal studies on postpartum depression around the world, there is a paucity of rigorous systemic data that explores not only the general burden of PPD, but also risk factors associated with it. The current understanding of the epidemiology of PPD is based mostly on a few geographic surveys and very little national evidence. Therefore, the present study aims to close this void by presenting an updated global estimate of postpartum depression epidemiology, synthesizing critical risk factors, and providing evidence-based data for maternal mental health treatment prioritization.

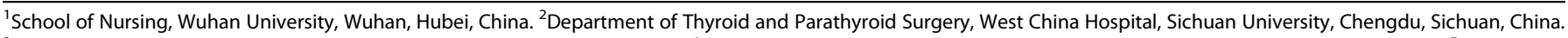
${ }^{3}$ Department of Orthopedics, Chengkou People's Hospital, Chongqing, China. ${ }^{4}$ Department of Nursing, Renmin Hospital of Wuhan University, Wuhan, Hubei, China. ${ }^{5}$ Department

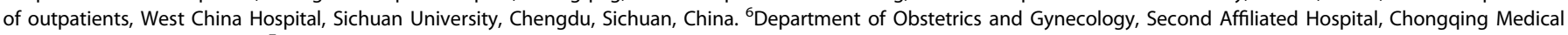
University, Chongqing, China. ${ }^{7}$ Chengdu Women's and Children's Central Hospital, School of Medicine, University of Electronic Science and Technology of China, Chengdu, China.

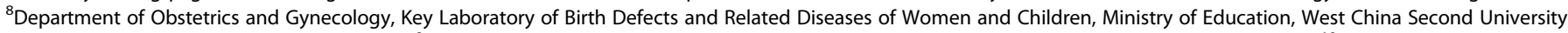

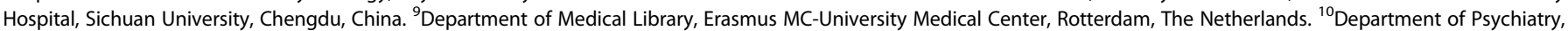

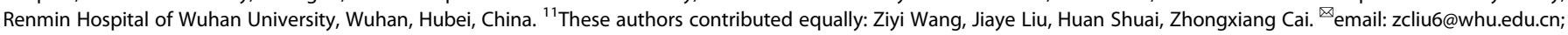
rockoliver@vip.sina.com; 00009312@whu.edu.cn
}

Received: 18 July 2021 Revised: 16 September 2021 Accepted: 27 September 2021

Published online: 20 October 2021 


\section{METHODS}

\section{Search strategy and selection criteria}

A systematic review and meta-analysis were done in accordance with PRISMA guidelines. Articles from inception to July 2021 were reviewed using the following databases: Medline, Embase, Web of Science, Cochrane, Psyclnfo and Google Scholar. Searches were tailored database functionality, but generally used the following terms: "postnatal depression", "postpartum depression", "depression" and "depressive symptoms". For relevant citations, reference lists of retrieved papers, as well as review articles found during the initial search, were screened. In order to uncover additional reports, forward citation checks were performed. Full details of the search strategy are provided in the Supplementary method.

Pre-defined decision rules were used to screen studies. Two reviewers independently screened titles and abstracts, with $10 \%$ of studies randomly reviewed by another investigator. Two investigators reviewed the complete texts of theoretically qualifying papers, with any inconsistencies settled through agreement or by another reviewer; consensus was found in all cases and agreement was reached.

Datasets from studies that met the following criteria were deemed eligible: (1) studies identified postpartum depressive disorder or depressive episode; (2) participants were women who completed assessments at least one week after giving birth in order to avoid baby blues being confused with PPD; (3) prevalence or incidence of depression was determined using standardized validated instruments, self-reported questionnaires, or clinically structured interviews; (4) participants were not recruited if they were receiving psychiatric assessment or care, or if they were identified as having possible depression because screening seeks to identify women with otherwise unrecognized major depression; (5) sufficient information was available for authors to calculate the aggregated prevalence of depression in the selected group of participants; and, (6) study undertaken from January, 2000 to July 2021.

\section{Data analysis}

Data extracted included the first author of the study, country or region, geographic region, time of publication, study period, income of country or region as assess by the World Bank, the level of country development, study category, study source, diagnostic technique, sample size, study quality and prevalence of disease (Supplementary Table 1). In addition, a comparison was made of the prevalence of postpartum depression stratified by marital status (married/cohabiting or single/divorced/widowed), employment (unemployed or paid employment), sex of infant (male or female), parity (primiparous or multiparous), educational level (less than 12 years or more than 12 years), social support from friends/ family/parents (YES/NO), support from partner (YES/NO), violence (YES/NO), maternal age (adolescent or adult), residence (urban or rural/suburb), religion (YES/NO), mode of delivery (spontaneous or instrumental/cesarean delivery), ethnicity (indigenous or nonindigenous/immigrant), location of delivery (home or health facility), gestational age (term or pre-/post-term), breast feeding (YES/NO), infant death (YES/NO), sleep (satisfactory or unsatisfactory), pregnancy planned (YES/NO), gender preference (YES/NO), financial problems (YES/NO), partnership (intimate/satisfactory or unsatisfied), life stress (YES/NO), smoker (YES/NO), alcohol use (YES/NO), family type (nuclear or extended), living condition (satisfactory/good or unsatisfactory) and number of children (1 or less/2 or more, Supplementary Table 2).

Socio-demographic characteristics of participants were identified and compared with the prevalence of postpartum depression to determine the pool estimates of risk factors for PPD. Data were cross-checked for accuracy against the original source. Researchers reviewed and extracted data from included studies by using a data extraction form specifically designed for the current study. When duplicate data were identified, the duplicate with the smallest sample size or shortest duration of follow-up was excluded.

The Joanna Briggs Institute-Checklist for Prevalence Studies was used to assess the methodological consistency of the qualifying studies (Supplementary Table 1). Based on quality score, studies were not omitted in order to improve clarity and to ensure that available data in this field was reported. After checking for consistency, the "Meta" and "Metafor" modules in the R-4.0.0 statistical software package were used for meta-analysis. A $95 \%$ confidence interval $(95 \% \mathrm{Cl}$ ) was estimated using the Wilson score method, and pooled prevalence was calculated with the DerSimonian-Laird random effects model with Logit transformation. Heterogeneity across included studies was assessed using Cochran $\mathrm{Q}$ and $\mathrm{I}^{2}$ statistics. Estimates with a $\mathrm{p}$ value lower than 0.05 for the Q-statistic and $\mathrm{I}^{2}$ of $50 \%$ or greater were considered to have moderate heterogeneity. A random-effects approach was used to pool the prevalence of postpartum depression as global evidence was assumed to be heterogeneous. A series of leave-one out diagnostic tests was performed by sensitivity analysis and findings were further checked using a build-in feature in Metafor. Using a Mixed-Effects Model, meta-regression was then conducted after eliminating the outliers. Covariates considered were geographic regions, development of countries or region, income of countries or regions, diagnostic techniques, publication time, study size and study quality score. Consequently, multivariable meta-regression (multi-model inference) was performed using a "dmetar" package to examine which possible predictor combinations provide the best fit, and which predictors are the most important ones overall. To assess the potential confounding effect of heterogeneity, subgroup analyses were performed. The $P$ value was used to compare the difference between the groups. A $P$ value $<0.05$ was considered as significant difference. The study protocol was registered at PROSPERO (https://www.crd.york.ac.uk/ prospero) as CRD42020211478.

\section{RESULTS}

\section{Literature search results and study characteristics}

The search identified 21,718 records, of which 10,758 records were retained after removing duplicates. Titles and abstracts were screened, resulting in the exclusion of 9,663 ineligible records. Full texts of the remaining 1,095 records were assessed for eligibility, of which 530 were excluded. Overall, 565 eligible studies involving 1,236,365 women were included in the final analysis (Fig. 1, Supplementary Table 1). The quality assessment scores of included studies are displayed in Supplementary Table 1. The majority of included studies had a cross-sectional design. The mean or median age of participants ranged from 17.76 to 37.70 years.

Participants included 172,342 women from 80 countries, having a diagnosis of postpartum depression. There was a high degree of heterogeneity among documented results with an overall prevalence rate of $17.22 \%\left(95 \% \mathrm{Cl} 16.00-18.51, I^{2}=99.70 \%\right.$, Table 1, Fig. 2).

In order to further understand the heterogeneity, sensitivity analysis was conducted by performing a set of leave-one out diagnostic tests (Supplementary Table 3 ) and the results were further verified by using a build-in function in Metafor (Supplementary Table 4 and Supplementary Fig. 1). As a result, four studies were identified as outliers for estimating pooled prevalence. After removing the outliers, the pooled prevalence of postpartum depression increased to $17.44 \%$ (95\% Cl 16.73-18.17, Fig. 3) stratified by countries or regions. To further explore the source of heterogeneity, meta-regression analysis was performed. The univariate meta-regression model indicated that geographical regions $\left(R^{2}=0, p=0.31\right)$, diagnostic scales $\left(R^{2}=0, p=0.37\right)$, publication year $\left(R^{2}=0, p=0.65\right)$, and quality score of the study $\left(R^{2}=0, \quad p=0.55\right) \quad$ were not significantly associated with 


\section{PRISMA 2009 Flow Diagram}
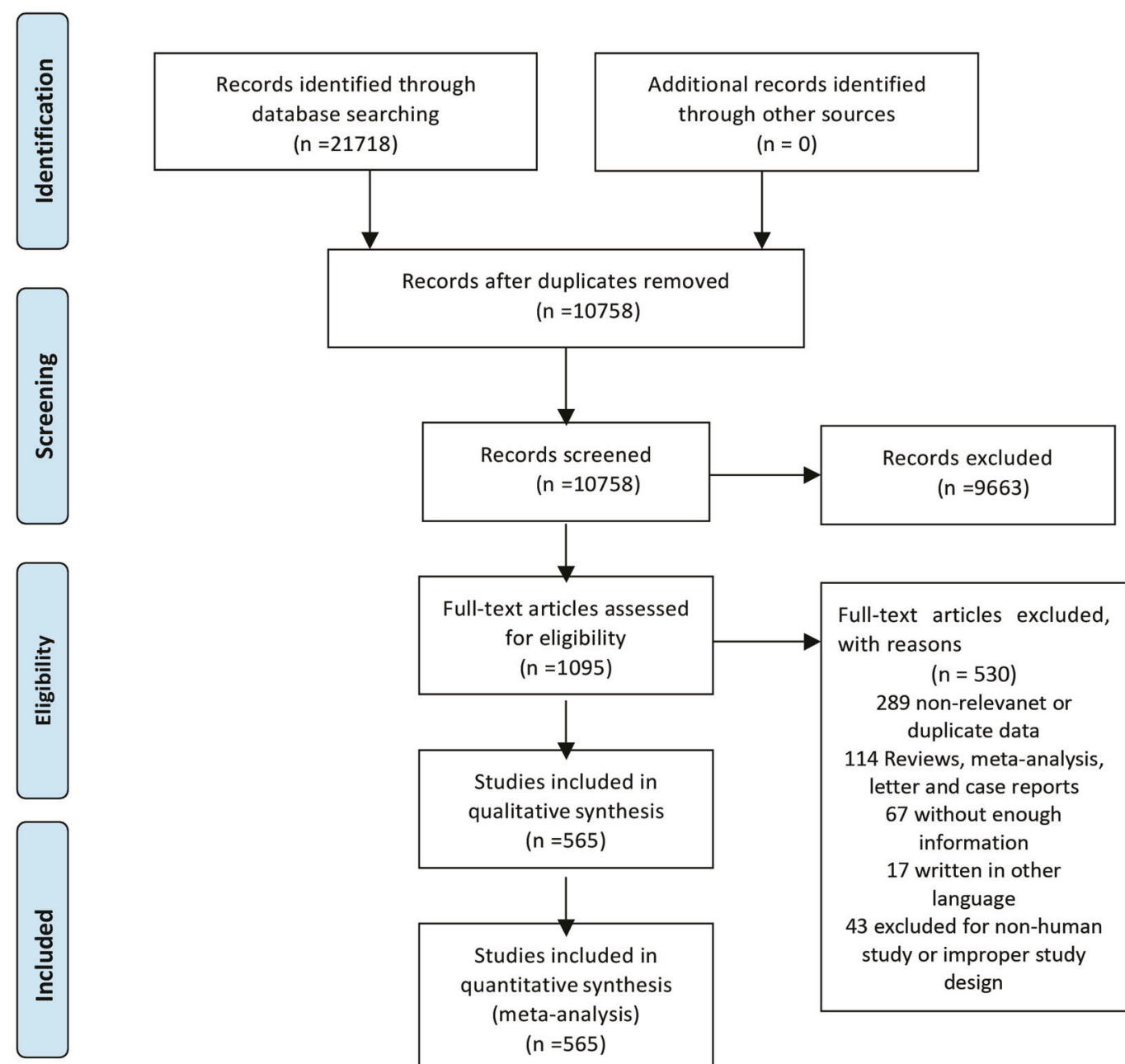

Fig. 1 Study selection. (Description of the searching methodology).

heterogeneity. The source of heterogeneity across the studies, identified by meta-regression analyses, was study size $\left(R^{2}=0.03\right.$, $p<0.01)$, development of countries or regions $\left(R^{2}=0.02, p<0.01\right)$ and income of countries or regions $\left(R^{2}=0, \mathrm{p}<0.01\right.$, Supplementary Table 4). By performing multivariable meta-regression, it was found that the study size and country or region development with the highest predictor importance of $99.99 \%$ (Fig. 4, Supplementary Table 5).

To confirm results of the meta-regression, subgroup analysis was performed after removing the outliers. Among geographic regions that had at least five studies, Southern Africa had the highest prevalence rate $(39.96 \%, 95 \% \mathrm{Cl} 27.81-53.48)$, followed by Southern Asia (22.32\%, 95\% Cl 18.48-26.70), South America (21.71\%, 95\% Cl 19.78-23.76), Western Asia (19.83\%, 95\% Cl 17.33-22.58), Northern Africa (18.75\%, 95\% Cl 11.40-29.26), Eastern Asia (17.39\%, 95\% Cl 16.09-18.77), Northern America (17.01\%, 95\% 15.68-18.44), Eastern Europe $(16.62 \%, 95 \% \mathrm{Cl}$ 10.95-24.43), Southern Europe $(16.34 \%, 95 \%$ Cl 12.90-20.48), Northern Europe $(13.78 \%, 95 \% \mathrm{Cl} 12.47-15.21)$, Western Africa (13.62\%, 95\% Cl 8.27-21.62), South-Eastern Asia (13.53\%, 95\% Cl
11.00-16.52), and Oceania (11.11\%, 95\% Cl 9.27-13.25, $p<0.01$, Table 1). Postpartum depression prevalence varied substantially among countries and regions, from 6.48\% (Denmark, 95\% Cl 5.707.36) to $60.93 \%$ (Afghanistan, $95 \% \mathrm{Cl} 54.25-67.22$, Fig. 2). Among countries or regions containing at least five relevant studies, South Africa had the highest $(38.79 \%, 95 \% \mathrm{Cl} 25.71-53.72)$ and Spain had the lowest $(9.09 \%, 95 \% \mathrm{Cl} 6.97-11.08)$ postpartum depression prevalence among women (Table 1). Considering the income of countries or regions, those with high incomes had a significantly lower prevalence of $15.54 \%(95 \% \mathrm{Cl} 14.90-16.20, p<0.01)$. Besides, developed countries $(14.85 \%, 95 \% \mathrm{Cl} 14.22-15.51)$ shared a significantly lower postpartum depression prevalence than that of developing countries (19.99\%, 95\% Cl 18.76-21.27, $p<0.01$, Table 1). With regard to diagnostic scales, use of the Postpartum Depression Screening Scale (PDSS) resulted in the highest postpartum depression prevalence rate $(37.23 \%, 95 \% \mathrm{Cl}$ 21.47-56.27) and the Structured Clinical Interview for DSM Disorders (SCID) with the lowest prevalence rate $(10.11 \%, 95 \%$ $\mathrm{Cl} 3.75-24.48)$. More than $80 \%$ of the studies used the Edinburgh Postnatal Depression Scale (EPDS) as their diagnostic tool with a 
Table 1. Subgroup analysis for PPD prevalence among women.

\begin{tabular}{|c|c|c|c|c|c|c|}
\hline Subgroup & Studies & Prevalence & PPD & Participants & $P$ value & $I^{2}$ \\
\hline Country & & & & & $<0.01$ & \\
\hline South Africa & 6 & $38.79(25.71-53.72)$ & 1076 & 3144 & & $98.00 \%$ \\
\hline Zambia & 1 & $9.71(6.74-13.79)$ & 27 & 278 & & \\
\hline Ghana & 4 & $8.00(1.90-28.13)$ & 606 & 4294 & & $99.30 \%$ \\
\hline Cote d'Ivoire & 1 & $14.13(10.90-18.11)$ & 51 & 361 & & \\
\hline Sudan & 2 & 7.56 (5.47-10.34) & 35 & 467 & & $0.00 \%$ \\
\hline Zimbabwe & 2 & $27.22(16.52-41.41)$ & 281 & 1137 & & $94.80 \%$ \\
\hline Ethiopia & 13 & $22.79(18.07-28.33)$ & 2666 & 11534 & & $97.50 \%$ \\
\hline Tanzania & 3 & $12.30(11.22-13.49)$ & 407 & 3310 & & $98.00 \%$ \\
\hline Nigeria & 7 & 17.93 (10.19-29.59) & 1008 & 10659 & & $0.00 \%$ \\
\hline Malaysia & 6 & $12.64(6.97-21.86)$ & 1021 & 10402 & & $98.80 \%$ \\
\hline China & 42 & $17.98(15.32-20.99)$ & 5946 & 31517 & & $97.10 \%$ \\
\hline Taiwan & 17 & $21.65(17.56-26.38)$ & 661 & 3141 & & $88.00 \%$ \\
\hline Vietnam & 8 & $13.77(8.54-21.47)$ & 1009 & 7314 & & $98.20 \%$ \\
\hline Pakistan & 3 & $35.45(18.47-57.10)$ & 440 & 1326 & & $97.60 \%$ \\
\hline United Arab Emirates & 1 & $18.31(10.94-29.03)$ & 13 & 71 & & - \\
\hline Nepal & 11 & $16.41(12.07-21.91)$ & 538 & 2443 & & $92.80 \%$ \\
\hline Thailand & 8 & $12.52(8.02-19.01)$ & 514 & 4547 & & $96.10 \%$ \\
\hline Singapore & 6 & $14.24(10.10-19.71)$ & 402 & 2602 & & $98.40 \%$ \\
\hline Oman & 2 & $16.38(9.15-27.58)$ & 160 & 874 & & $90.60 \%$ \\
\hline Brazil & 31 & $20.51(18.53-22.65)$ & 19960 & 88955 & & $98.00 \%$ \\
\hline Poland & 5 & $17.91(9.19-31.97)$ & 365 & 2013 & & $97.60 \%$ \\
\hline Spain & 5 & 9.09 (6.97-11.78) & 360 & 3704 & & $84.10 \%$ \\
\hline UK & 13 & $21.50(17.63-25.94)$ & 25786 & 219769 & & $98.40 \%$ \\
\hline Sweden & 14 & $12.18(9.41-15.63)$ & 2057 & 18189 & & $97.20 \%$ \\
\hline Kuwait & 1 & $11.72(10.11-13.55)$ & 158 & 1348 & & - \\
\hline Norway & 12 & $11.24(8.31-15.03)$ & 1711 & 12557 & & $97.00 \%$ \\
\hline Iran & 18 & $24.41(17.18-33.43)$ & 5834 & 15753 & & $99.20 \%$ \\
\hline Kenya & 3 & $25.20(11.50-46.63)$ & 70 & 391 & & $90.50 \%$ \\
\hline Jordan & 4 & $39.78(21.43-61.54)$ & 539 & 1333 & & $98.20 \%$ \\
\hline Uganda & 1 & $32.67(27.60-38.18)$ & 98 & 300 & & - \\
\hline Indonesia & 2 & $11.76(3.73-31.43)$ & 51 & 440 & & $93.90 \%$ \\
\hline Eswatini & 1 & $47.37(38.39-56.52)$ & 54 & 114 & & - \\
\hline Syria & 1 & $28.24(25.66-30.96)$ & 312 & 1105 & & - \\
\hline Saudi Arabia & 7 & $20.08(14.17-27.65)$ & 457 & 2305 & & $93.40 \%$ \\
\hline New Zealand & 5 & $10.58(5.62-19.01)$ & 681 & 8057 & & $98.30 \%$ \\
\hline Multi & 3 & $20.21(10.16-36.19)$ & 233 & 1474 & & $96.60 \%$ \\
\hline Morocco & 1 & $27.00(19.22-36.51)$ & 27 & 100 & & - \\
\hline
\end{tabular}




\begin{tabular}{|c|c|c|c|c|c|c|}
\hline Subgroup & Studies & Prevalence & PPD & Participants & $P$ value & $I^{2}$ \\
\hline Portugal & 4 & $18.28(12.57-25.81)$ & 115 & 663 & & $77.90 \%$ \\
\hline Netherlands & 7 & $10.69(5.76-18.98)$ & 1222 & 13069 & & $99.10 \%$ \\
\hline Ireland & 3 & $11.14(10.13-12.25)$ & 1275 & 11694 & & $19.10 \%$ \\
\hline Iraq & 1 & $28.40(25.69-31.28)$ & 284 & 1000 & & - \\
\hline Hungary & 1 & $16.54(12.54-21.50)$ & 44 & 266 & & - \\
\hline Lebanon & 1 & $12.75(8.28-19.13)$ & 19 & 149 & & - \\
\hline Korea & 4 & $22.50(12.01-38.17)$ & 246 & 1263 & & $96.10 \%$ \\
\hline Finland & 3 & $14.62(9.83-21.20)$ & 320 & 2513 & & $92.20 \%$ \\
\hline Denmark & 2 & $6.48(5.70-7.36)$ & 219 & 3381 & & $0.00 \%$ \\
\hline Mexico & 1 & $20.00(15.13-25.96)$ & 42 & 210 & & - \\
\hline Hong Kong & 4 & $16.96(13.77-20.70)$ & 321 & 1860 & & $71.90 \%$ \\
\hline Greenland & 1 & $8.62(5.26-13.81)$ & 15 & 174 & & - \\
\hline Germany & 3 & $9.76(5.26-17.40)$ & 161 & 1760 & & $92.90 \%$ \\
\hline Bahrain & 1 & $37.13(31.21-43.46)$ & 88 & 237 & & - \\
\hline Serbia & 3 & $23.66(10.41-45.27)$ & 134 & 573 & & $95.60 \%$ \\
\hline Peru & 1 & $29.97(28.00-32.02)$ & 597 & 1992 & & - \\
\hline Armenia & 2 & $14.08(11.48-17.14)$ & 82 & 583 & & $0.00 \%$ \\
\hline Mongolia & 1 & $9.10(7.50-11.00)$ & 95 & 1044 & & - \\
\hline Russia & 2 & $13.54(1.71-58.45)$ & 205 & 820 & & $97.80 \%$ \\
\hline Continent & & & & & $<0.01$ & \\
\hline Southern Africa & 7 & $39.96(27.81-53.48)$ & 1130 & 3258 & & $97.70 \%$ \\
\hline Eastern Africa & 26 & $20.21(16.86-24.04)$ & 3665 & 17780 & & $97.00 \%$ \\
\hline Western Africa & 12 & $13.62(8.27-21.62)$ & 1665 & 25314 & & $99.00 \%$ \\
\hline Northern Africa & 9 & $18.75(11.40-29.26)$ & 534 & 2785 & & $96.90 \%$ \\
\hline Western Asia & 62 & $19.83(17.33-22.58)$ & 7133 & 34950 & & $97.20 \%$ \\
\hline Eastern Asia & 96 & 17.39 (16.09-18.77) & 32429 & 238273 & & $97.70 \%$ \\
\hline Southern Asia & 56 & $22.32(18.48-26.70)$ & 9964 & 35227 & & $98.80 \%$ \\
\hline South-eastern Asia & 33 & $13.53(11.00-16.52)$ & 3208 & 26677 & & $97.30 \%$ \\
\hline Northern America & 92 & $17.01(15.68-18.44)$ & 47816 & 361247 & & $98.70 \%$ \\
\hline Oceania & 28 & $11.11(9.27-13.25)$ & 7609 & 90737 & & $98.30 \%$ \\
\hline South America & 37 & $21.71(19.78-23.76)$ & 20899 & 92201 & & $97.80 \%$ \\
\hline Western Europe & 20 & $12.91(9.44-17.40)$ & 1952 & 18372 & & $97.90 \%$ \\
\hline Eastern Europe & 10 & $16.62(10.95-24.43)$ & 673 & 3507 & & $96.50 \%$ \\
\hline Northern Europe & 47 & $13.78(12.47-15.21)$ & 31368 & 268103 & & $97.20 \%$ \\
\hline Southern Europe & 31 & $16.34(12.90-20.48)$ & 1997 & 16177 & & $96.60 \%$ \\
\hline Central America & 1 & $20.00(15.13-25.96)$ & 42 & 210 & & $96.70 \%$ \\
\hline Caribbean & 1 & $34.25(24.31-45.79)$ & 25 & 73 & & - \\
\hline Multiple & 3 & $20.21(10.16-36.19)$ & 233 & 1474 & & - \\
\hline
\end{tabular}


Table 1 continued

\begin{tabular}{|c|c|c|c|c|c|c|}
\hline Subgroup & Studies & Prevalence & PPD & Participants & $P$ value & $I^{2}$ \\
\hline Development & & & & & $<0.01$ & \\
\hline Developing & 295 & $19.99(18.76-21.27)$ & 54145 & 266334 & & $98.30 \%$ \\
\hline Developed & 276 & $14.85(14.22-15.51$ & 118197 & 970031 & & $98.20 \%$ \\
\hline Country or regional income & & & & & $<0.01$ & \\
\hline High & 314 & $15.54(14.90-16.20)$ & 121333 & 985634 & & $98.20 \%$ \\
\hline Upper-middle & 178 & $19.68(18.26-21.19)$ & 41217 & 186768 & & $98.40 \%$ \\
\hline Low & 23 & $20.02(15.32-25.73)$ & 4023 & 24855 & & $98.70 \%$ \\
\hline Publication date & & & & & 0.58 & \\
\hline Before 2010 & 145 & $17.94(15.79-20.30)$ & 19417 & 120264 & & $98.80 \%$ \\
\hline After 2010 & 426 & $17.28(16.54-18.05)$ & 152925 & 1116101 & & $98.80 \%$ \\
\hline Study size & & & & & $<0.01$ & \\
\hline SRQ & 12 & $25.90(21.16-31.27)$ & 3681 & 12948 & & $97.70 \%$ \\
\hline PHQ-9 & 19 & $18.59(12.21-27.44)$ & 2475 & 23846 & & $99.10 \%$ \\
\hline EPDS & 464 & $16.86(16.04-17.72)$ & 110611 & 775287 & & $98.70 \%$ \\
\hline CES-D & 13 & $25.06(19.55-31.50)$ & 2763 & 19702 & & $97.80 \%$ \\
\hline $\mathrm{BDI}$ & 10 & $29.70(23.07-37.31)$ & 553 & 1767 & & $89.30 \%$ \\
\hline DASS & 4 & $18.47(16.43-20.70)$ & 1234 & 6863 & & $72.40 \%$ \\
\hline SCID & 5 & $10.11(3.75-24.48)$ & 1712 & 6360 & & $98.90 \%$ \\
\hline PDSS & 5 & $37.23(21.47-56.27)$ & 471 & 1522 & & $97.50 \%$ \\
\hline SDS & 4 & $28.17(21.30-36.24)$ & 1231 & 4248 & & $95.90 \%$ \\
\hline PHQ-2 & 5 & $18.47(14.42-23.34)$ & 14461 & 105902 & & $99.30 \%$ \\
\hline 3 months -6 months & 89 & $15.92(14.03-18.02)$ & 26031 & 277293 & & $99.10 \%$ \\
\hline 6 months -12 months & 67 & 17.89 (13.32-23.59) & 55092 & 1560464 & & $99.90 \%$ \\
\hline Longer than 12 months & 15 & $17.95(13.80-23.01)$ & 1781 & 11374 & & $96.60 \%$ \\
\hline
\end{tabular}

prevalence rate of $16.86 \%(95 \% \mathrm{Cl} 16.04-17.72$, Table 1). Interestingly, a pattern of increased prevalence rates was found in studies having more than 1,000 participants $(12.97 \%, 95 \% \mathrm{Cl}$ $18.40-20.51)$ than those with less than 1,000 participants $(19.44 \%$, $95 \% \mathrm{Cl} 18.40-20.51, p<0.01$, Table 1). To be noted, postpartum depression appears to be universally prevalent in 1-3 months (17.70\%, 95\% Cl 15.95-19.60), 3-6 months $(15.31 \%, 95 \% \mathrm{Cl}$ 14.31-16.36), 6-12 months (18.19\%, 95\% Cl 13.56-23.96) and greater than 12 months $(17.95 \%, 95 \% \mathrm{Cl} 13.80-23.01, p=0.08$, Table 1) after birth.

Moreover, results indicated that a significant difference in PPD prevalence was found in the pooled estimate among marital status (married/cohabiting or single/divorced/widowed, $16.37 \%$ vs. $28.14 \%, p<0.01$ ), educational level (less than 12 years or more than 12 years, $19.84 \%$ vs. $15.66 \%, p<0.01)$, social support from friends/family/parents (YES/NO, $15.15 \%$ vs. $32.03 \%, p<0.01$ ), support from partner (YES/NO, 15.40\% vs. 35.99\%, $p<0.01$ ), violence (YES/NO, $40.40 \%$ vs. $15.65 \%, p<0.01$ ), gestational age (term or pre-/post-term, $15.48 \%$ vs. $22.04 \%, p=0.01$ ), breast feeding (YES/NO, $16.51 \%$ vs. $25.02 \%, p<0.01$ ), infant death (YES/ NO, $43.33 \%$ vs. $18.50 \%, p<0.01$ ), planned pregnancy (YES/NO, $17.36 \%$ vs. $28.12 \%, p<0.01$ ), financial problems (YES/NO, $31.82 \%$ vs. $15.92 \%, p<0.01$ ), partnership (intimate/satisfied or unsatisfied, $17.11 \%$ vs. $39.96 \%, p<0.01$ ), life stress (YES/NO, $28.81 \%$ vs. $14.53 \%, p<0.01$ ), smoker (YES/NO, $25.17 \%$ vs. $15.74 \%, p<0.01$ ), alcohol use (YES/NO, $20.97 \%$ vs. $14.49 \%, p=0.02$ ) and living conditions (satisfied/well or unsatisfied, $20.35 \%$ vs. $38.82 \%, p=$ 0.02). However, minimal differences were observed among number of children ( 1 or less $/ 2$ or more, $17.74 \%$ vs. $19.38 \%, p=$ 0.68 ), employment (unemployed or paid employment, $21.08 \%$ vs. $18.29 \%, p=0.11$ ), sex of infant (male or female, $17.97 \%$ vs. $20.77 \%$, $p=0.13$ ), parity (primiparous or multiparous, $17.39 \%$ vs. $17.63 \%, p$ $=0.92$ ), maternal age (adolescent or adult, $23.34 \%$ vs. $20.35, p=$ 0.52 ), residence (urban or rural/suburb, $12.10 \%$ vs. $14.46 \%, p=$ 0.73 ), religion (YES/NO, $15.11 \%$ vs. $17.47 \%, p=0.77$ ), mode of delivery (spontaneous or instrumental/cesarean delivery, $18.31 \%$ 


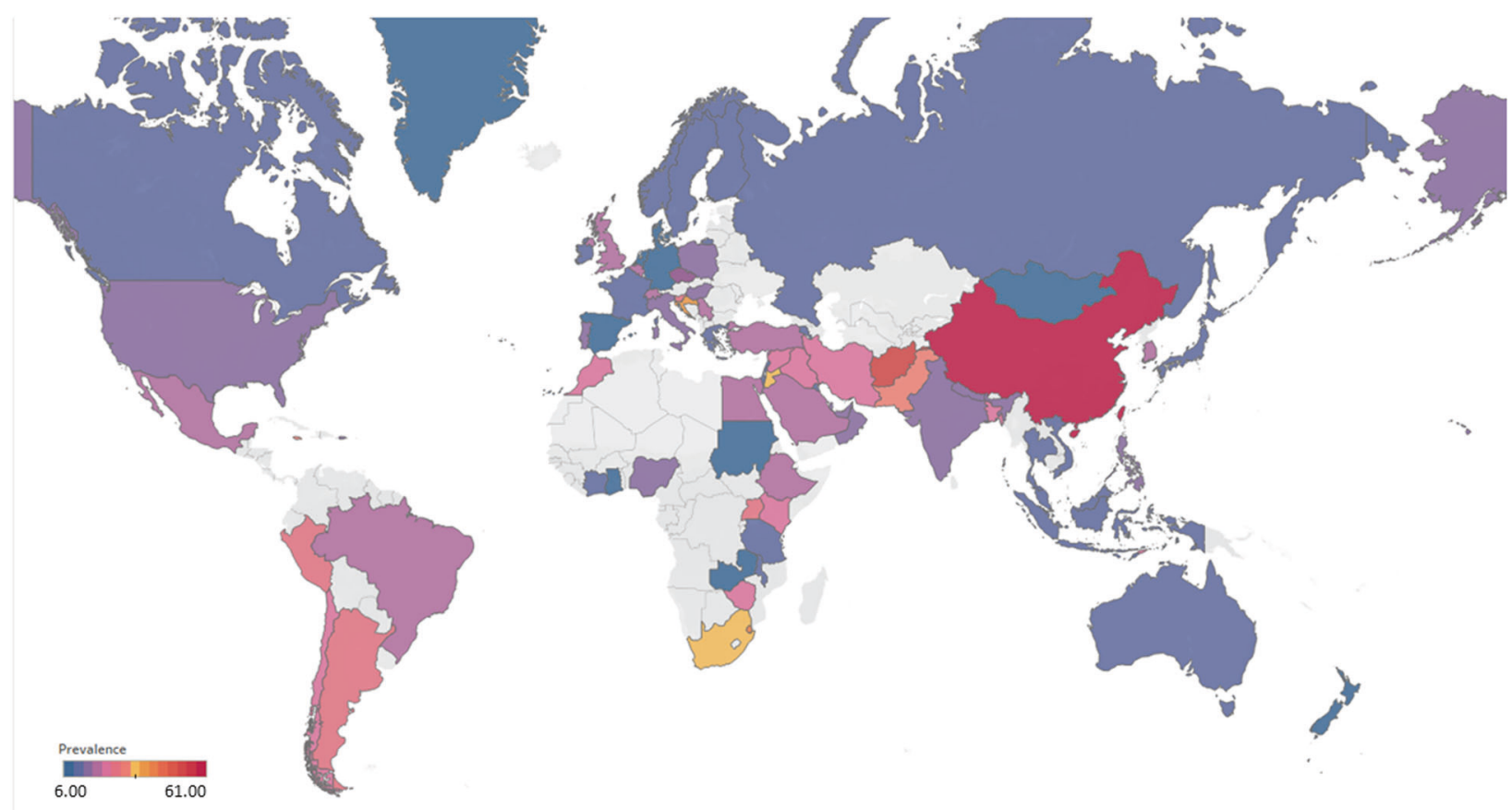

Fig. 2 Global prevalence of postpartum depression. (Unbalanced prevalence of postpartum depression was observed between different continents, countries and regions).

vs. $21.01 \%, p=0.40$ ), ethnicity (indigenous or nonindigenous/ immigrant, $14.76 \%$ vs. $17.06 \%, p=0.27$ ), location of delivery (home or health facility, $14.88 \%$ vs. $11.08 \%, p=0.49$ ), sleep (satisfactory or unsatisfactory, $17.20 \%$ vs. $30.78 \%, p=0.08$ ), family type (nuclear or extended, $20.66 \%$ vs. $21.15 \%, p=0.82$ ) and gender preference (YES/NO, $17.78 \%$ vs. $13.82 \%, p=0.40$, Table 2 ).

\section{DISCUSSION}

The global prevalence of PPD was found to be approximately $17.22 \%$ (95\% Cl 16.00-18.51) in the largest meta-analysis of PPD to-date. Study findings revealed significant differences between geographic regions, with Southern Africa having the highest prevalence rate $(39.96 \%, 95 \%$ $\mathrm{Cl}$ 27.81-53.48). Furthermore, country development and income inequalities had a major effect on PPD epidemiology. Furthermore, it was discovered that the prevalence of various variables such as marital status, educational level, violence, partnership, life stress, smoking, alcohol use, and living conditions differed significantly. However, no significant difference in PPD was noted in relation to infant gender and gender preference.

There have been recent systematic reviews of PPD worldwide [1013] or in specific regions, including Asia [14, 15] and Africa [16], but to the researchers' knowledge this is the most comprehensive review with the largest number of studies on PPD globally. Results showed that the estimates are significantly higher than the widely cited prevalence rate of $13 \%(95 \% \mathrm{Cl}: 12.3-13.4 \%)$, derived from a metaanalysis of studies from developed countries [10] and lower than the $19 \%$ prevalence rate for PPD derived from studies of relatively lowand middle-income countries [12]. Interestingly, the current study findings are more similar to pooled estimates of PPD when using the EPDS [13]. Furthermore, current findings revealed that the prevalence of PPD was closely linked to country development and national or regional income. This is in line with previous research, which has shown that developing countries with low or lower-middle income have a higher prevalence of PPD. Importantly, the PPD prevalence rate varied based on the scale used when comparisons were made between countries with different socioeconomic structures. Previous studies had observed inconsistent PPD prevalence with 1.9\% to $82.1 \%$ in developed countries, and $5.2 \%$ to $74 \%$ in developing countries [17]. Moreover, another study evaluated PPD studies from 40 countries and reported the prevalence of PPD to be $10-15 \%$ and found this prevalence to vary between $0 \%$ and $60 \%$ in developed and developing countries, respectively [9]. One detailed study found that PPD prevalence in developing countries was greater in developing countries $(31.1 \%)$ than that of developed countries $(21.5 \%)$ in rural areas [18]. It is worth noting that even among nations in similar economic strata, there are differences in national estimates of the prevalence of postpartum depression. For example, the prevalence of PPD in the United Kingdom is $21.5 \%$, while that in New Zealand, another high-income country, is $10.58 \%$; PPD prevalence in Ghana and Egypt were $3 \%$ and $22.99 \%$ respectively, while in fact they belong to low-income countries and their per capita GDP is similar.

Almost all geographic regions were represented in this review, with the highest coverage in Eastern Asia $(n=96)$ and the lowest coverage in Central America and Caribbean areas $(n=1)$. As a result, the current study's pooled estimates of Central America and the Caribbean are underrepresented. Furthermore, the current analysis showed substantial variations between graphic areas on the same continent. Southern Asia, for instance, led with the highest prevalence $(22.32 \%, 95 \% \mathrm{Cl} 18.48-26.70)$, followed by Western Asia (19.83\%, 95\% Cl 17.33-22.58), Eastern Asia (17.39\%, 95\% Cl 16.09-18.77), and South-Eastern Asia (13.53\%, 95\% Cl $11.00-16.52)$. This was mirrored in the vast spectrum of PPD prevalence in Asian countries, which ranged from $9.29 \%$ (Korea) to $60.93 \%$ (Afghanistan). These findings matched those of a previous study, which found that Asians made up 3.5\% to $63.3 \%$ of the population [19]. To be noted, current study results indicated the prevalence in Southern Asia and Western Asia were significantly higher than that of Northern America, Europe, and Oceania. This is largely in accordance with the results from previous studies [20]. Differences in cultural traditions may play a role in this disparity. In those areas, girls tended to marry at an early age. But when it comes to age as a risk factor, the literature is conflicting. Some studies discovered that mothers with younger 


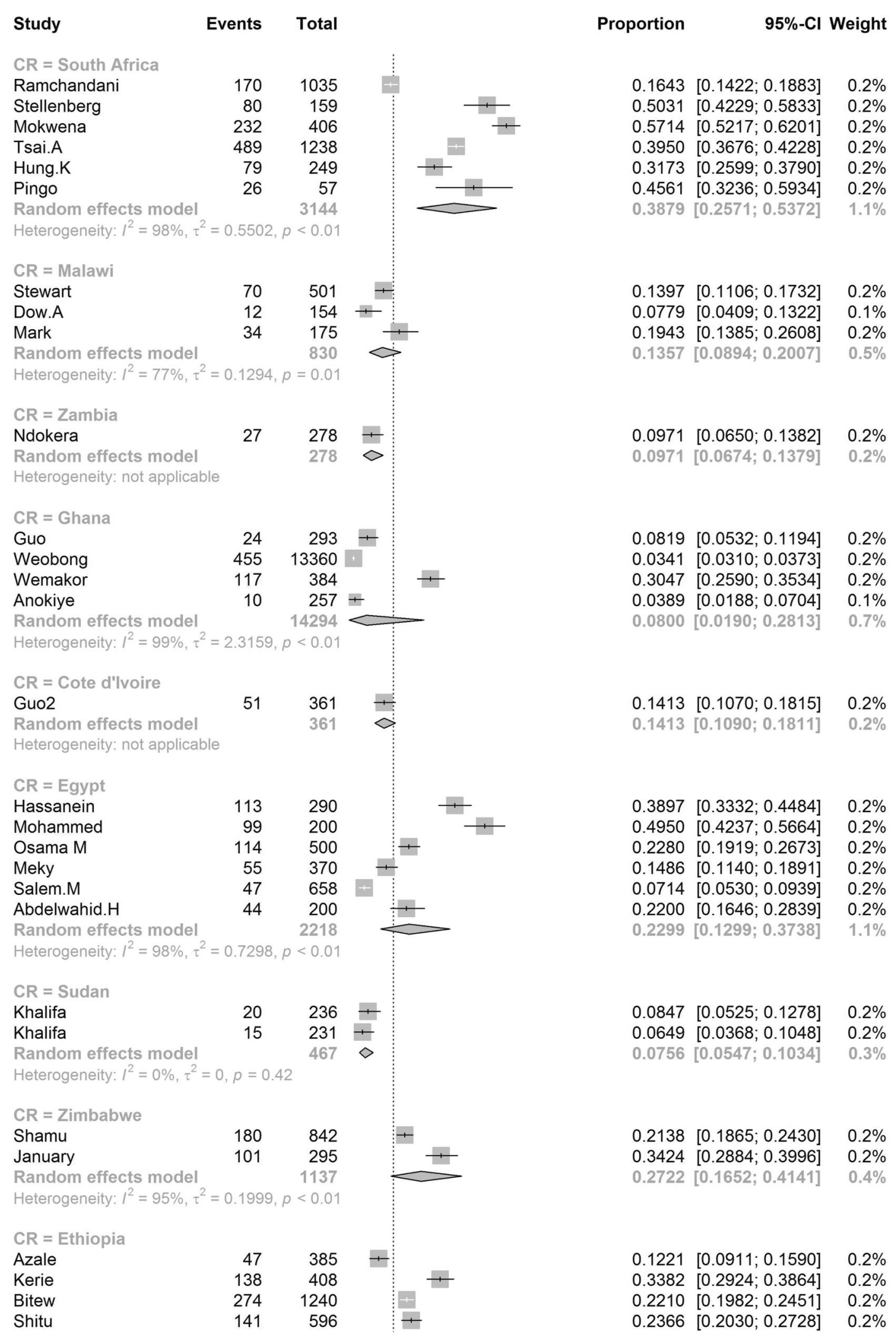

Fig. 3 Forest plot of prevalence of postpartum depression stratified by countries or regions. (Postpartum depression prevalence varied substantially between different countries and regions, with the lowest prevalence observed in Denmark and highest one in Afghanistan).

children are more likely to develop PPD [21, 22], while other studies discovered that older age is related to PPD [23, 24]. No differences were found in a case-control study conducted by Balaha and colleagues [25]. To be noted, in the current study, the pooled estimates suggest a marginally higher PPD prevalence in adolescent mothers than adult mothers without significant difference. In addition, relationships with mothers-in-law were closely correlated with PPD in those women [23]. In these research 


\begin{tabular}{|c|c|c|c|c|}
\hline Asaye & 129 & 526 & & + \\
\hline Adamu & 144 & 618 & & + \\
\hline Abebe & 113 & 511 & & + \\
\hline Wubetu & 48 & 308 & $\div$ & 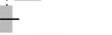 \\
\hline Necho.M & 102 & 378 & & + \\
\hline Abadiga.M & 60 & 287 & & 1 \\
\hline Upadhyay.A & 652 & 1811 & & + \\
\hline Azale.T & 385 & 3147 & + & \\
\hline Baumgartner.J & 433 & 1319 & & + \\
\hline Random effects model & & 11534 & & $\infty$ \\
\hline \multicolumn{5}{|c|}{ Heterogeneity: $l^{2}=98 \%, \tau^{2}=0.2773, p<0.01$} \\
\hline \multicolumn{5}{|l|}{ CR $=$ Tanzania } \\
\hline Rogathi & 122 & 1013 & + & \\
\hline Wesselhoeft.R3 & 147 & 1169 & + & \\
\hline Holm-Larsen & 138 & 1128 & + & \\
\hline Random effects model & & 3310 & $\diamond$ & \\
\hline \multicolumn{5}{|c|}{ Heterogeneity: $I^{2}=0 \%, \tau^{2}=0, p=0.93$} \\
\hline \multicolumn{5}{|l|}{$C R=\mid$ Israel } \\
\hline Glasser & 65 & 288 & & + \\
\hline Shwartz & 116 & 1121 & + & \\
\hline Glasser & 36 & 104 & & 1 \\
\hline Samira & 175 & 564 & & + \\
\hline Simhi & 84 & 1000 & + & \\
\hline Glasser & 379 & 2326 & & \\
\hline Shwartz & 109 & 1055 & + & \\
\hline Lichter & 14 & 312 & + & \\
\hline Freedman & 22 & 143 & + & \\
\hline Goren & 7 & 114 & + & \\
\hline Orbach-Zinger & 87 & 1326 & + & \\
\hline Bina & 94 & 805 & + & \\
\hline Random effects model & & 9158 & $\infty$ & \\
\hline \multicolumn{5}{|c|}{ Heterogeneity: $I^{2}=97 \%, \tau^{2}=0.3720, p<0.01$} \\
\hline \multicolumn{5}{|l|}{ CR = Japan } \\
\hline Yoshida & 14 & 93 & 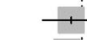 & \\
\hline Murakami & 121 & 865 & + & \\
\hline Mishina & 78 & 630 & +1 & \\
\hline Shimizu & 17 & 65 & & + \\
\hline Motoko & 19 & 70 & & + \\
\hline Miyake & 121 & 865 & + & \\
\hline Watanabe & 30 & 235 & + & \\
\hline Atsuko & 39 & 169 & & 1 \\
\hline Nishigori & 135 & 633 & & + \\
\hline Hiroko.I & 103 & 479 & & + \\
\hline Yuko.O & 21 & 154 & $+:$ & \\
\hline Tsuruko.M & 72 & 675 & + & \\
\hline Yoshihiro.M & 106 & 771 & + & \\
\hline Hamazaki & 9761 & 84181 & 1 & \\
\hline Maeda & 196 & 977 & & + \\
\hline Yamada & 536 & 6195 & + & \\
\hline Maher.A & 146 & 1048 & + & \\
\hline Miyake & 108 & 1316 & + & \\
\hline Nakano.M & 93 & 1050 & + & \\
\hline Mishina.H & 17 & 103 & $\longrightarrow$ & \\
\hline Amemiya & 614 & 6461 & + & \\
\hline Miura & 955 & 6534 & + & \\
\hline Nakamura & 138 & 1033 & + & \\
\hline Iwata & 241 & 2709 & + & \\
\hline Takehara & 83 & 1306 & + & \\
\hline Ikeda & 16 & 76 & - & 1 \\
\hline Muchanga & 11255 & 80396 & 1 & \\
\hline Random effects model & & 199089 & $\Delta$ & \\
\hline \multicolumn{5}{|c|}{ Heterogeneity: $I^{2}=96 \%, \tau^{2}=0.0463, p<0.01$} \\
\hline
\end{tabular}

$0.2452 \quad[0.2090 ; 0.2843] \quad 0.2 \%$

$0.2330[0.2002 ; 0.2684] \quad 0.2 \%$

$0.2211 \quad[0.1859 ; 0.2597] \quad 0.2 \%$

$0.1558[0.1172 ; 0.2013] \quad 0.2 \%$

$0.2698[0.2257 ; 0.3176] \quad 0.2 \%$

$0.2091[0.1635 ; 0.2607] \quad 0.2 \%$

$0.3600[0.3379 ; 0.3826] \quad 0.2 \%$

$0.1223[0.1111 ; 0.1343] \quad 0.2 \%$

$0.3283[0.3030 ; 0.3544] \quad 0.2 \%$

$0.2279[0.1807 ; 0.2833] \quad 2.4 \%$

$0.1204[0.1010 ; 0.1421] \quad 0.2 \%$

$0.1257[0.1073 ; 0.1461] \quad 0.2 \%$

$0.1223[0.1038 ; 0.1429] \quad 0.2 \%$

$0.1230[0.1122 ; 0.1346] \quad 0.6 \%$

$0.2257[0.1787 ; 0.2784] \quad 0.2 \%$

$0.1035[0.0863 ; 0.1228] \quad 0.2 \%$

$0.3462[0.2555 ; 0.4458] \quad 0.2 \%$

$0.3103[0.2723 ; 0.3503] \quad 0.2 \%$

$0.0840[0.0676 ; 0.1029] \quad 0.2 \%$

$0.1629[0.1481 ; 0.1786] \quad 0.2 \%$

$0.1033[0.0856 ; 0.1233] \quad 0.2 \%$

$0.0449[0.0247 ; 0.0741] \quad 0.2 \%$

$0.1538[0.0990 ; 0.2236] \quad 0.2 \%$

$0.0614[0.0250 ; 0.1224] \quad 0.1 \%$

$0.0656[0.0529 ; 0.0803] \quad 0.2 \%$

$0.1168[0.0954 ; 0.1410] \quad 0.2 \%$

$0.1290[0.0938 ; 0.1750] \quad 2.1 \%$

$0.1505[0.0848 ; 0.2397] \quad 0.2 \%$

$0.1399[0.1174 ; 0.1648] \quad 0.2 \%$

$0.1238[0.0991 ; 0.1521] \quad 0.2 \%$

$0.2615[0.1603 ; 0.3854] \quad 0.2 \%$

$0.2714[0.1720 ; 0.3910] \quad 0.2 \%$

$0.1399[0.1174 ; 0.1648] \quad 0.2 \%$

$0.1277[0.0878 ; 0.1772] \quad 0.2 \%$

$0.2308 \quad[0.1695 ; 0.3017] \quad 0.2 \%$

$0.2133[0.1820 ; 0.2473] \quad 0.2 \%$

$0.2150[0.1791 ; 0.2546] \quad 0.2 \%$

$0.1364[0.0864 ; 0.2009] \quad 0.2 \%$

$0.1067[0.0844 ; 0.1324] \quad 0.2 \%$

$0.1375[0.1140 ; 0.1638] \quad 0.2 \%$

$0.1160[0.1138 ; 0.1181] \quad 0.2 \%$

$0.2006[0.1759 ; 0.2271] \quad 0.2 \%$

$0.0865[0.0796 ; 0.0938] \quad 0.2 \%$

$0.1393[0.1189 ; 0.1618] \quad 0.2 \%$

$0.0821[0.0678 ; 0.0982] \quad 0.2 \%$

$0.0886[0.0721 ; 0.1074] \quad 0.2 \%$

0.1650 [0.0992; 0.2511$] \quad 0.2 \%$

$0.0950[0.0880 ; 0.1024] \quad 0.2 \%$

$0.1462[0.1377 ; 0.1550] \quad 0.2 \%$

$0.1336[0.1134 ; 0.1559] \quad 0.2 \%$

$0.0890[0.0785 .0 .1003] \quad 0.2 \%$

$0.0636[0.0509 ; 0.0782] \quad 0.2 \%$

$0.2105[0.1254 ; 0.3192] \quad 0.2 \%$

$0.1400[0.1376 ; 0.1424] \quad 0.2 \%$

$0.1330[0.1225 ; 0.1443] \quad 4.8 \%$

Fig. 3 (Continued).

participants, mothers-in-law tend to be essential to the survival of the marriage, as sons remain closely attached to their families of birth, frequently living with and even working within the family company their entire lives. Mothers-in-law often exercise a considerable amount of leverage over their daughters-in-law and grandchildren's lives. As a result, having a healthy relationship with one's mother-in-law is crucial in a woman's life, and having a negative one can lead to depression. Moreover, other risk factors, 


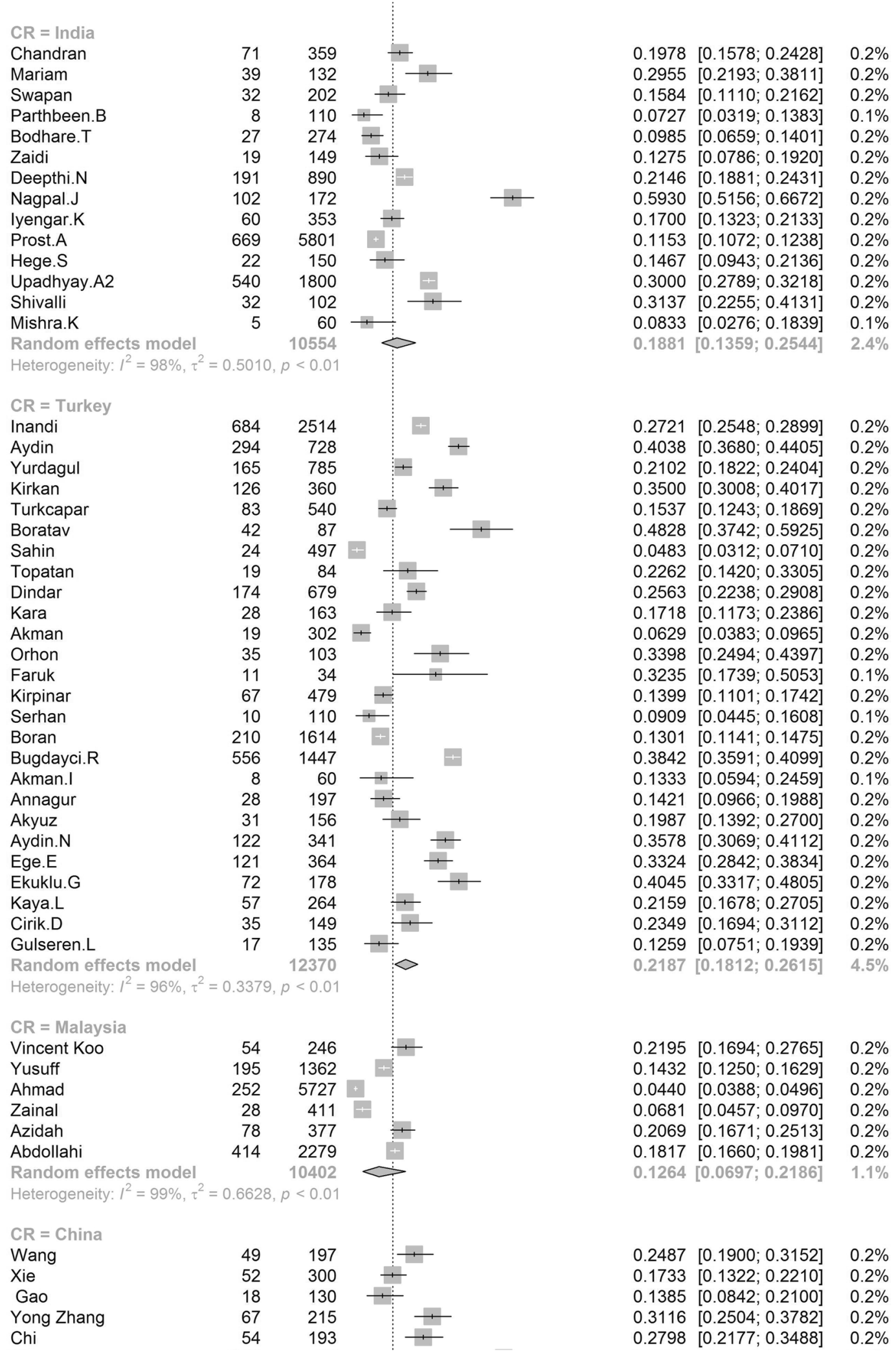

Fig. 3 (Continued).

such as postpartum rituals including the period of 40 days resting, restricted activities, and diets [26], multiple children [27] and unemployment $[21,28]$ were also correlated with a high prevalence rate.
Previous studies indicated that the past history of depression significantly enhanced the chance of PPD [29, 30]. That explains why studies on new mothers having perinatal depression were not included in pooled estimates. Fifteen 


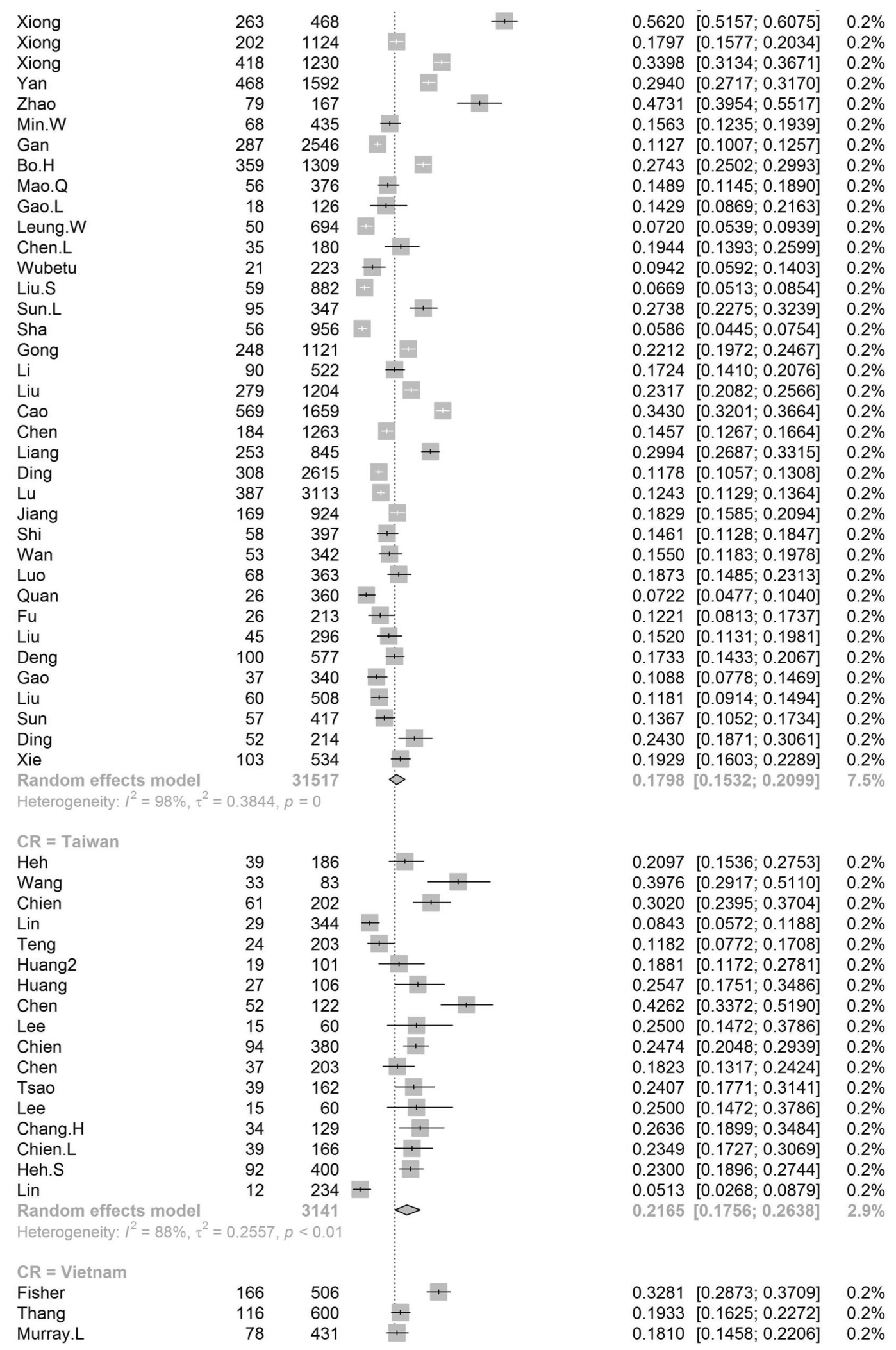

Fig. 3 (Continued).

factors were found related to an elevated risk of PPD in the current review. In terms of breastfeeding, it is generally thought to be a possible preventive factor, and it was found that starting breastfeeding reduced the likelihood of depression in this current research. Breastfeeding has also been linked to an elevated risk of PPD in several trials. Underlying variables such as the mother's background traits may be a source of confusion. Moreover, breastfeeding 


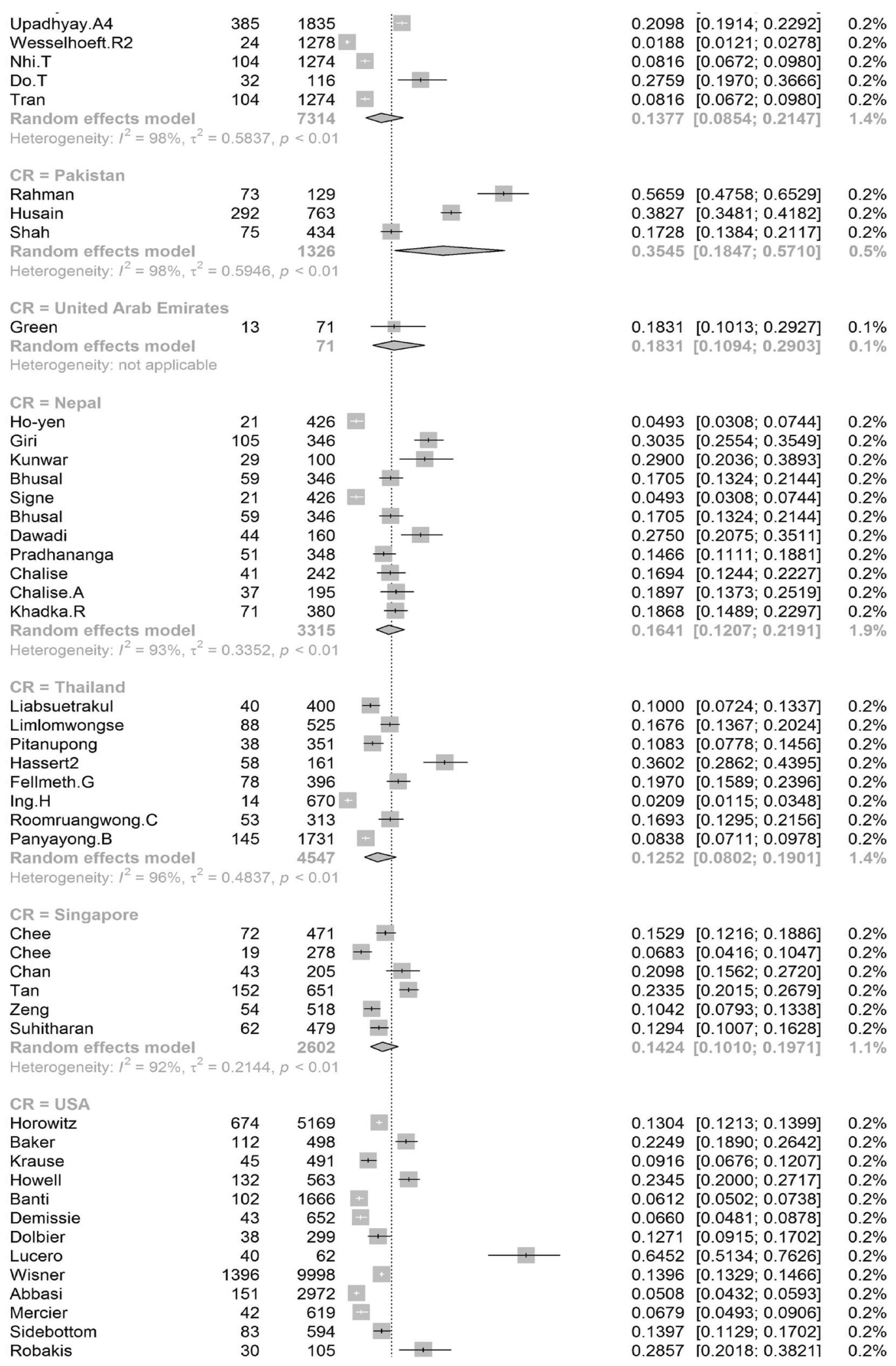

Fig. 3 (Continued).

duration and breastfeeding self-efficacy may also be correlated with PPD [31, 32]. Besides, according to the findings of the study, postpartum women face a variety of stressful life activities, including relationships, financial problems, social support, and maternal stressors. More than three-quarters of depressed postpartum women (78.2\%) reported they had strained ties with their mothers-in-law [21]. With a strong correlation with their counterparts, almost half of postpartum 


\begin{tabular}{|c|c|c|c|c|c|c|}
\hline Corrigan & 13 & 61 & $\begin{array}{l}1+1 \\
\vdots 1\end{array}$ & 0.2131 & {$[0.1186 ; 0.3368]$} & $0.1 \%$ \\
\hline Kim & 96 & 223 & $\quad+$ & 0.4305 & {$[0.3646 ; 0.4983]$} & $0.2 \%$ \\
\hline Sandraluz & 6 & 28 & 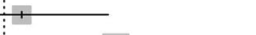 & 0.2143 & {$[0.0830 ; 0.4095]$} & $0.1 \%$ \\
\hline Kim & 95 & 223 & $\longrightarrow$ & 0.4260 & {$[0.3602 ; 0.4938]$} & $0.2 \%$ \\
\hline Badr & 4 & 25 & & 0.1600 & {$[0.0454 ; 0.3608]$} & $0.1 \%$ \\
\hline Khalil & 29 & 115 & 1 & 0.2522 & {$[0.1758 ; 0.3417]$} & $0.2 \%$ \\
\hline Beck.C & 379 & 903 & + & 0.4197 & {$[0.3873 ; 0.4527]$} & $0.2 \%$ \\
\hline McCoy.S & 81 & 209 & $\div$ & 0.3876 & {$[0.3211 ; 0.4572]$} & $0.2 \%$ \\
\hline Appolonio.K & 17 & 87 & 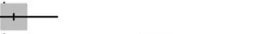 & 0.1954 & {$[0.1181 ; 0.2943]$} & $0.2 \%$ \\
\hline Boury.J & 77 & 151 & $\longrightarrow$ & 0.5099 & {$[0.4274 ; 0.5921]$} & $0.2 \%$ \\
\hline Mayberry.L & 422 & 1359 & + & 0.3105 & {$[0.2860 ; 0.3359]$} & $0.2 \%$ \\
\hline Miles.M & 64 & 103 & 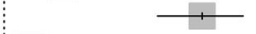 & 0.6214 & {$[0.5204 ; 0.7151]$} & $0.2 \%$ \\
\hline Cheng.C & 36 & 152 & 1 & 0.2368 & {$[0.1717 ; 0.3125]$} & $0.2 \%$ \\
\hline Logsdon.M & 72 & 156 & -1 & 0.4615 & {$[0.3815 ; 0.5431]$} & $0.2 \%$ \\
\hline Paulson.J & 733 & 5089 & & 0.1440 & {$[0.1345 ; 0.1540]$} & $0.2 \%$ \\
\hline Stone & 804 & 5395 & & 0.1490 & {$[0.1396 ; 0.1588]$} & $0.2 \%$ \\
\hline Lynch & 5365 & 40337 & & 0.1330 & {$[0.1297 ; 0.1364]$} & $0.2 \%$ \\
\hline Pooler & 10382 & 75234 & & 0.1380 & {$[0.1355 ; 0.1405]$} & $0.2 \%$ \\
\hline Schachman & 36 & 71 & 1 & 0.5070 & {$[0.3856 ; 0.6278]$} & $0.2 \%$ \\
\hline Sweeney & 5 & $46 \longrightarrow$ & & 0.1087 & {$[0.0362 ; 0.2357]$} & $0.1 \%$ \\
\hline Dagher & 34 & $526+$ & & 0.0646 & {$[0.0452 ; 0.0892]$} & $0.2 \%$ \\
\hline Gress-Smith & 47 & 132 & 1 & 0.3561 & {$[0.2747 ; 0.4441]$} & $0.2 \%$ \\
\hline Kornfeld & 8 & 36 & 1 & 0.2222 & {$[0.1012 ; 0.3915]$} & $0.1 \%$ \\
\hline Gjerdingen & 34 & 463 & & 0.0734 & {$[0.0514 ; 0.1011]$} & $0.2 \%$ \\
\hline Murphy & 12 & $+\vdots$ & 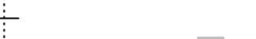 & 0.1237 & {$[0.0656 ; 0.2061]$} & $0.1 \%$ \\
\hline Le & 141 & 220 & 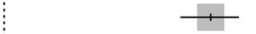 & 0.6409 & {$[0.5737 ; 0.7043]$} & $0.2 \%$ \\
\hline Sorenson & 11 & 71 & & 0.1549 & {$[0.0800 ; 0.2603]$} & $0.1 \%$ \\
\hline McGrath & 17 & 128 & & 0.1328 & {$[0.0793 ; 0.2041]$} & $0.2 \%$ \\
\hline Pantbangi.V & 94 & 530 & $\div$ & 0.1774 & {$[0.1458 ; 0.2126]$} & $0.2 \%$ \\
\hline Yawn.B & 73 & 481 & & 0.1518 & {$[0.1209 ; 0.1870]$} & $0.2 \%$ \\
\hline Ward & 1535 & 10231 & & 0.1500 & {$[0.1432 ; 0.1571]$} & $0.2 \%$ \\
\hline Jenny.S & 60 & 587 & & 0.1022 & {$[0.0789 ; 0.1296]$} & $0.2 \%$ \\
\hline Nicklas.J & 24 & 71 & 1 & 0.3380 & {$[0.2300 ; 0.4601]$} & $0.2 \%$ \\
\hline Eisenach.J & 144 & 1288 & & 0.1118 & {$[0.0951 ; 0.1303]$} & $0.2 \%$ \\
\hline Certain.H & 153 & 1519 & & 0.1007 & {$[0.0860 ; 0.1170]$} & $0.2 \%$ \\
\hline Dagher.R & 30 & $638+$ & & 0.0470 & {$[0.0319 ; 0.0664]$} & $0.2 \%$ \\
\hline Gaffney.K & 349 & 1447 & + & 0.2412 & {$[0.2193 ; 0.2641]$} & $0.2 \%$ \\
\hline Glynn.L & 34 & 170 & 1 & 0.2000 & {$[0.1427 ; 0.2681]$} & $0.2 \%$ \\
\hline Elizabeth.A & 34 & 242 & & 0.1405 & {$[0.0993 ; 0.1908]$} & $0.2 \%$ \\
\hline Knight.J & 8 & $191+$ & & 0.0419 & {$[0.0183 ; 0.0809]$} & $0.1 \%$ \\
\hline Mott.S & 11 & $147 \div$ & & 0.0748 & {$[0.0379 ; 0.1299]$} & $0.1 \%$ \\
\hline Silverman.M & 94 & 439 & 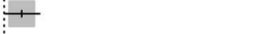 & 0.2141 & {$[0.1766 ; 0.2555]$} & $0.2 \%$ \\
\hline Watkin.S & 222 & 2586 & & 0.0858 & {$[0.0753 ; 0.0973]$} & $0.2 \%$ \\
\hline Wei & 147 & 586 & + & 0.2509 & {$[0.2162 ; 0.2880]$} & $0.2 \%$ \\
\hline Gregory & 346 & 1501 & + & 0.2305 & {$[0.2094 ; 0.2527]$} & $0.2 \%$ \\
\hline Emerson & 31 & 200 & & 0.1550 & {$[0.1078 ; 0.2127]$} & $0.2 \%$ \\
\hline Birmingham & 45 & 195 & 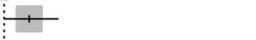 & 0.2308 & {$[0.1736 ; 0.2963]$} & $0.2 \%$ \\
\hline Kothari & 30 & 301 & & 0.0997 & {$[0.0683 ; 0.1392]$} & $0.2 \%$ \\
\hline Faisal-Cury & 133 & 315 & + & 0.4222 & {$[0.3671 ; 0.4789]$} & $0.2 \%$ \\
\hline Bauman & 4311 & 32659 & & 0.1320 & {$[0.1283 ; 0.1357]$} & $0.2 \%$ \\
\hline Haight & 2825 & 23990 & & 0.1178 & {$[0.1137 ; 0.1219]$} & $0.2 \%$ \\
\hline Farr & 181 & 2012 & & 0.0900 & {$[0.0778 ; 0.1033]$} & $0.2 \%$ \\
\hline Farr & 1558 & 4451 & + & 0.3500 & {$[0.3360 ; 0.3643]$} & $0.2 \%$ \\
\hline Random effects model & & 242105 & $\vdots$ & 0.1856 & {$[0.1691 ; 0.2034]$} & $11.4 \%$ \\
\hline \multicolumn{7}{|c|}{ Heterogeneity: $I^{2}=99 \%, \tau^{2}=0.1898, p=0$} \\
\hline \multicolumn{7}{|l|}{ CR $=$ Australia } \\
\hline Ogbo & 425 & 12757 & & 0.0333 & {$[0.0303 ; 0.0366]$} & $0.2 \%$ \\
\hline McMahon & 43 & 541 & & 0.0795 & {$[0.0581 ; 0.1056]$} & $0.2 \%$ \\
\hline Austin & 53 & 575 & & 0.0922 & {$[0.0698 ; 0.1188]$} & $0.2 \%$ \\
\hline Edwards & 33 & 154 & 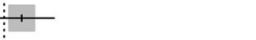 & 0.2143 & {$[0.1523 ; 0.2876]$} & $0.2 \%$ \\
\hline Milgrom & 925 & 12361 & & 0.0748 & {$[0.0703 ; 0.0796]$} & $0.2 \%$ \\
\hline Yelland.J & 743 & 4269 & + & 0.1740 & {$[0.1628 ; 0.1858]$} & $0.2 \%$ \\
\hline McMahanon.C & 51 & 114 & 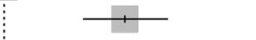 & 0.4474 & {$[0.3542 ; 0.5434]$} & $0.2 \%$ \\
\hline Eastwood & 2317 & 25455 & & 0.0910 & $\lceil 0.0875 ; 0.0946\rceil$ & $0.2 \%$ \\
\hline
\end{tabular}

Fig. 3 (Continued).

mothers with depression reported having more than one stressful life events, such as low income $(58.1 \%)$ and unplanned pregnancy $(60.4 \%)$ [21]. Baker et al. found that low socioeconomic status, unwanted pregnancy and stressful life events during pregnancy have been associated with postpartum mental disorders [33]. Current study results are consistent with previous studies that unplanned pregnancy and a lack of family care were found to be important correlates of PPD. Support 


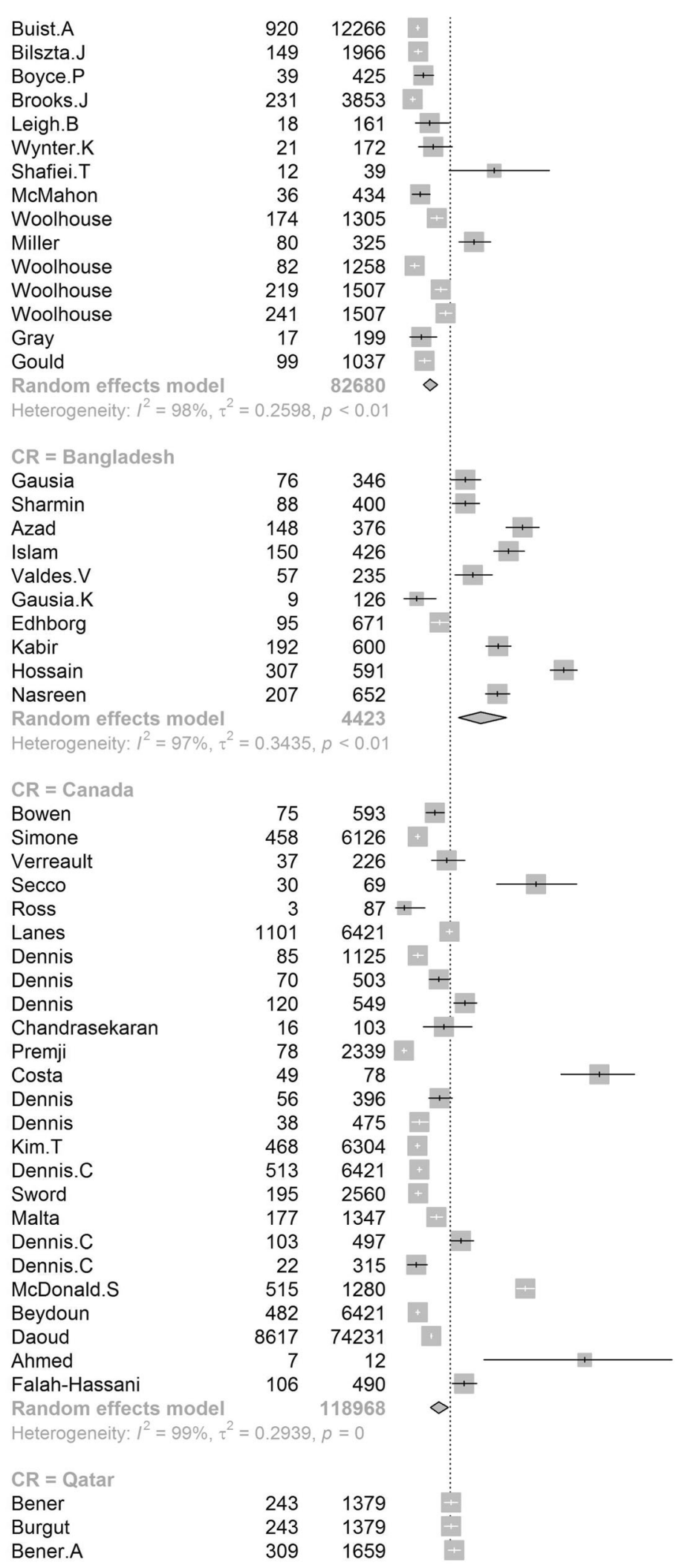

$0.0750[0.0704 ; 0.0798]$

$0.0758[0.0645 ; 0.0884]$

$0.0918 \quad[0.0661 ; 0.1233]$

$0.0600[0.0527 ; 0.0679]$

$0.1118[0.0676 ; 0.1709]$

$0.1221[0.0772 ; 0.1806]$

$0.3077[0.1702 ; 0.4757]$

$0.0829[0.0588 ; 0.1130]$

$0.1333[0.1153 ; 0.1530]$

$0.2462[0.2003 ; 0.2967]$

$0.0652[0.0522 ; 0.0803]$

$0.1453[0.1279 ; 0.1641]$

$0.1599[0.1418 ; 0.1794]$

$0.0854[0.0506 ; 0.1333]$

$0.0955[0.0783 ; 0.1150]$

$0.1122[0.0923 ; 0.1356]$

$0.2197[0.1771 ; 0.2670]$

$0.2200[0.1804 ; 0.2638]$

$0.3936[0.3439 ; 0.4450]$

$0.3521 \quad[0.3067 ; 0.3995]$

$0.2426[0.1892 ; 0.3025]$

$0.0714[0.0332 ; 0.1313]$

$0.1416[0.1161 ; 0.1703]$

$0.3200[0.2828 ; 0.3590]$

$0.5195[0.4783 ; 0.5604]$

$0.3175[0.2819 ; 0.3547]$

$0.2665[0.2000 ; 0.3456]$

$0.2 \%$

$0.2 \%$

$0.2 \%$

$0.2 \%$

$0.2 \%$

$0.1 \%$

$0.2 \%$

$0.2 \%$

$0.2 \%$

$0.2 \%$

$1.8 \%$

$0.1265[0.1008 ; 0.1559]$

$0.0748[0.0683 ; 0.0816]$

$0.1637[0.1180 ; 0.2185]$

$0.4348[0.3158 ; 0.5596]$

$0.0345[0.0072 ; 0.0975]$

$0.1715[0.1623 ; 0.1809]$

$0.0756[0.0608 ; 0.0926]$

$0.1392[0.1101 ; 0.1725]$

$0.2186[0.1847 ; 0.2555]$

$0.1553[0.0915 ; 0.2400]$

$0.0333[0.0264 ; 0.0414]$

$0.6282[0.5113 ; 0.7350]$

$0.1414[0.1086 ; 0.1797]$

$0.0800[0.0572 ; 0.1082]$

$0.0742[0.0679 ; 0.0810]$

$0.0799[0.0734 ; 0.0868]$

$0.0762[0.0662 ; 0.0871]$

$0.1314[0.1138 ; 0.1506]$

$0.2072[0.1724 ; 0.2456]$

$0.0698[0.0443 ; 0.1038]$

$0.4023[0.3753 ; 0.4298]$

$0.0751[0.0687 ; 0.0818]$

$0.1161[0.1138 ; 0.1184]$

$0.5833[0.2767 ; 0.8483]$

$0.2163[0.1807 ; 0.2555]$

$0.1389[0.1143 ; 0.1679]$

$0.2 \%$

$0.2 \%$

$0.2 \%$

$0.2 \%$

$0.1 \%$

$0.2 \%$

$0.2 \%$

$0.2 \%$

$0.2 \%$

$0.2 \%$

$0.2 \%$

$0.2 \%$

$0.2 \%$

$0.2 \%$

$0.2 \%$

$0.2 \%$

$0.2 \%$

$0.2 \%$

$0.2 \%$

$0.2 \%$

$0.2 \%$

$0.2 \%$

$0.2 \%$

$0.1 \%$

$0.2 \%$

$4.3 \%$

$\begin{array}{lll}0.1762[0.1564 ; 0.1974] & 0.2 \% \\ 0.1762[0.1564 ; 0.1974] & 0.2 \% \\ 0.1863[0.1678 ; 0.2058] & 0.2 \%\end{array}$

Fig. 3 (Continued).

should be considered a protective factor based on the literature described previously [21, 34, 35]. Our findings are in line with previous research that support from partners, family members, and friends is shown to be adversely associated with the likelihood of PPD in the current study. The current study also found that women in financial difficulties or experiencing stressful events were at increased risk for PPD. This finding was confirmed in systematic reviews 


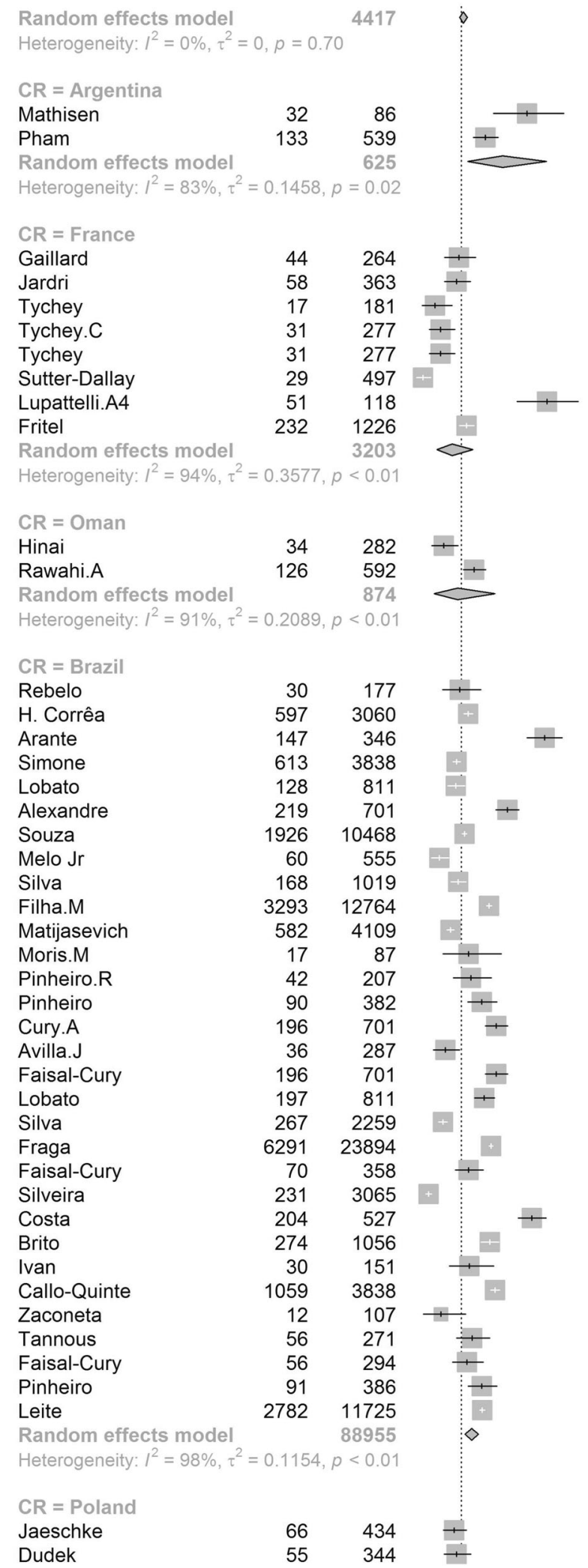

$0.1800[0.1690 ; 0.1916] \quad 0.6 \%$

$0.3721[0.2702 ; 0.4830] \quad 0.2 \%$

$0.2468[0.2109 ; 0.2854] \quad 0.2 \%$

$0.2988[0.1930 ; 0.4314] \quad 0.3 \%$

$0.1667 \quad[0.1238 ; 0.2172] \quad 0.2 \%$

$0.1598[0.1236 ; 0.2016] \quad 0.2 \%$

$0.0939[0.0557 ; 0.1461] \quad 0.2 \%$

$0.1119[0.0773 ; 0.1551] \quad 0.2 \%$

$0.1119[0.0773 \cdot 0.1551] \quad 0.2 \%$

$0.0584[0.0394 ; 0.0827] \quad 0.2 \%$

$0.4322[0.3413 ; 0.5266] \quad 0.2 \%$

$0.1892[0.1677 ; 0.2123] \quad 0.2 \%$

$0.1463[0.1001 ; 0.2089] \quad 1.4 \%$

$0.1206[0.0850 ; 0.1644] \quad 0.2 \%$

$0.2128[0.1805 ; 0.2480] \quad 0.2 \%$

$0.1638[0.0915 ; 0.2758] \quad 0.4 \%$

$0.1695[0.1174 ; 0.2330] \quad 0.2 \%$

$0.1951[0.1812 ; 0.2096] \quad 0.2 \%$

$0.4249[0.3722 ; 0.4788] \quad 0.2 \%$

$0.1597[0.1483 ; 0.1717] \quad 0.2 \%$

$0.1578[0.1334 ; 0.1848] \quad 0.2 \%$

$0.3124[0.2782 ; 0.3482] \quad 0.2 \%$

$0.1840[0.1766 ; 0.1915] \quad 0.2 \%$

$0.1081[0.0835 ; 0.1370] \quad 0.2 \%$

$0.1649[0.1426 ; 0.1891] \quad 0.2 \%$

$0.2580[0.2504 ; 0.2657] \quad 0.2 \%$

$0.1416[0.1311 ; 0.1527] \quad 0.2 \%$

$0.1954[0.1181 ; 0.2943] \quad 0.2 \%$

$0.2029[0.1503 ; 0.2642] \quad 0.2 \%$

$0.2356[0.1939 ; 0.2814] \quad 0.2 \%$

$0.2796[0.2467 ; 0.3144] \quad 0.2 \%$

$0.1254[0.0894 ; 0.1694] \quad 0.2 \%$

$0.2796[0.2467 ; 0.3144] \quad 0.2 \%$

$0.2429[0.2138 ; 0.2739] \quad 0.2 \%$

$0.1182[0.1052 ; 0.1322] \quad 0.2 \%$

$0.2633[0.2577 ; 0.2689] \quad 0.2 \%$

$0.1955[0.1557 ; 0.2405] \quad 0.2 \%$

$0.0754[0.0663 ; 0.0853] \quad 0.2 \%$

$0.3871[0.3453 ; 0.4302] \quad 0.2 \%$

$0.2595[0.2333 ; 0.2870] \quad 0.2 \%$

$0.1987[0.1382 ; 0.2713] \quad 0.2 \%$

$0.2759[0.2618 ; 0.2904] \quad 0.2 \%$

$0.1121[0.0593 ; 0.1877] \quad 0.1 \%$

$0.2066[0.1600 ; 0.2598] \quad 0.2 \%$

$0.1905[0.1472 ; 0.2401] \quad 0.2 \%$

$0.2358[0.1943 ; 0.2813] \quad 0.2 \%$

$0.2373[0.2296 ; 0.2451] \quad 0.2 \%$

$0.2051[0.1853 ; 0.2265] \quad 5.6 \%$

$0.1521 \quad[0.1196 ; 0.1894] \quad 0.2 \%$

0.1599 [0.1228; 0.2030$] \quad 0.2 \%$

Fig. 3 (Continued).

and meta-analyses conducted in low- and middle-income countries [36]. Due to lack of financial support, women in financial difficulties may be in a state of poverty, which leads to stress [36]. To be noted, our results indicated that mothers experiencing domestic violence were almost three times more likely than their counterparts to suffer from depression. Other studies found that postpartum depression was linked to mothers having a history of domestic violence and abuse from 


\begin{tabular}{|c|c|c|c|c|}
\hline Lupattelli.A9 & 138 & 300 & & \\
\hline Maliszewska & 48 & 387 & + & \\
\hline Maliszewska & 58 & 548 & + & \\
\hline Random effects model & & 2013 & $<$ & $\Longrightarrow$ \\
\hline \multicolumn{5}{|c|}{ Heterogeneity: $I^{2}=98 \%, \tau^{2}=0.7480, p<0.01$} \\
\hline \multicolumn{5}{|l|}{$C R=$ Spain } \\
\hline Koutra & 141 & 1037 & + & \\
\hline Vicenta & 25 & 360 & + & \\
\hline Alfonso & 42 & 525 & + & \\
\hline Albacar & 65 & 729 & + & \\
\hline Albacar & 87 & 1053 & + & \\
\hline Random effects model & & 3704 & $\diamond$ & \\
\hline \multicolumn{5}{|c|}{ Heterogeneity: $I^{2}=84 \%, \tau^{2}=0.0885, p<0.01$} \\
\hline \multicolumn{5}{|l|}{ CR = UK } \\
\hline Afolabi & 23 & 32 & & \\
\hline Petersen & 23623 & 206517 & 1 & \\
\hline Huang & 9 & 50 & & \\
\hline Edge & 39 & 200 & & $\div$ \\
\hline Heron & 27 & 203 & $+\vdots$ & \\
\hline Shelton & 97 & 399 & & + \\
\hline Husain & 63 & 237 & & + \\
\hline Brown & 32 & 217 & + & \\
\hline Qandil & 28 & 101 & & $\longrightarrow$ \\
\hline Edge.D & 96 & 301 & & ? \\
\hline Morrell.C & 595 & 4084 & + & \\
\hline Lupattelli.A2 & 209 & 676 & & + \\
\hline Fellmeth & 945 & 6752 & + & \\
\hline Random effects model & & 219769 & & $\infty$ \\
\hline \multicolumn{5}{|c|}{ Heterogeneity: $I^{2}=98 \%, \tau^{2}=0.1742, p<0.01$} \\
\hline \multicolumn{5}{|l|}{ CR = Nigeria } \\
\hline Afolabi2 & 15 & 79 & - & + \\
\hline Agbaje & 92 & 270 & & + \\
\hline Adewuya & 128 & 876 & + & \\
\hline Bakare.M & 101 & 408 & & + \\
\hline Abiodun & 67 & 360 & & + \\
\hline Adewuya.A & 15 & 86 & 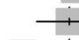 & ; \\
\hline Oladeji.B & 590 & 8580 & + & \\
\hline Random effects model & & 10659 & $<$ & \\
\hline \multicolumn{5}{|c|}{ Heterogeneity: $I^{2}=98 \%, \tau^{2}=0.7502, p<0.01$} \\
\hline \multicolumn{5}{|l|}{ CR $=$ Sweden } \\
\hline Eckerdal & 505 & 3888 & + & \\
\hline Sara & 166 & 1610 & + & \\
\hline Sara & 239 & 2318 & + & \\
\hline Iliadis & 83 & 975 & + & \\
\hline Eckerdal.P & 193 & 1503 & + & \\
\hline Kerstis & 50 & 305 & 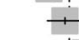 & + \\
\hline Edvinsson & 33 & 157 & & - \\
\hline Sylven.S & 42 & 653 & + & \\
\hline Lupattelli.A6 & 104 & 416 & & + \\
\hline Sunnqvist & 175 & 1747 & + & \\
\hline Eckerdal & 53 & 446 & + & \\
\hline Sarberg & 29 & 293 & + & \\
\hline Asif & 138 & 2990 & + & \\
\hline Rosander & 247 & 888 & & + \\
\hline Random effects model & & 18189 & $\diamond$ & \\
\hline \multicolumn{5}{|c|}{ Heterogeneity: $I^{2}=97 \%, \tau^{2}=0.2899, p<0.01$} \\
\hline$C R=$ Kuwait & & & & \\
\hline Pampaka & 158 & 1348 & + & \\
\hline $\begin{array}{l}\text { Random effects model } \\
\text { Heterogeneity: not applicable }\end{array}$ & & 1348 & $\diamond$ & \\
\hline
\end{tabular}

$0.4600 \quad[0.4026 ; 0.5182]$ $0.1240[0.0929 ; 0.1611]$ $0.1058[0.0814 ; 0.1347]$

$0.1791[0.0919 ; 0.3197]$

$0.2 \%$ $0.2 \%$ $0.2 \%$ $0.9 \%$

$0.1360[0.1157 ; 0.1583]$ $0.0694[0.0454 ; 0.1008]$ $0.0800[0.0583 ; 0.1066]$ $0.0892[0.0695 ; 0.1122]$ $0.0826[0.0667 ; 0.1009]$

$0.0909[0.0697 ; 0.1178]$

$0.2 \%$ $0.2 \%$ $0.2 \%$ $0.2 \%$ $0.2 \%$ $0.9 \%$

$0.7188[0.5325 ; 0.8625] \quad 0.1 \%$ $0.1144[0.1130 ; 0.1158] \quad 0.2 \%$ $0.1800[0.0858 ; 0.3144] \quad 0.1 \%$ $0.1950[0.1425 ; 0.2568] \quad 0.2 \%$ $0.1330[0.0895 ; 0.1876] \quad 0.2 \%$ $0.2431[0.2018 ; 0.2883] \quad 0.2 \%$ $0.2658[0.2107 ; 0.3269] \quad 0.2 \%$ $0.1475[0.1031 ; 0.2018] \quad 0.2 \%$ $0.2772[0.1928 ; 0.3752] \quad 0.2 \%$ $0.3189[0.2666 ; 0.3748] \quad 0.2 \%$ $0.1457[0.1350 ; 0.1569] \quad 0.2 \%$ $0.3092[0.2745 ; 0.3455] \quad 0.2 \%$ 0.1400 [0.1318;0.1485] $0.2 \%$ $0.2150[0.1763 ; 0.2594] \quad 2.2 \%$

$0.1899[0.1103 ; 0.2938] \quad 0.2 \%$ $0.3407[0.2844 ; 0.4006] \quad 0.2 \%$ $0.1461[0.1234 ; 0.1713] \quad 0.2 \%$ $0.2475[0.2064 ; 0.2924] \quad 0.2 \%$ $0.1861[0.1472 ; 0.2302] \quad 0.2 \%$ $0.1744[0.1010 ; 0.2713] \quad 0.2 \%$ $0.0688[0.0635 ; 0.0743] \quad 0.2 \%$ $0.1793[0.1019 ; 0.2959] \quad 1.2 \%$

$0.1299[0.1195 ; 0.1409] \quad 0.2 \%$ $0.1031[0.0887 ; 0.1190] \quad 0.2 \%$ $0.1031[0.0910 ; 0.1162] \quad 0.2 \%$ $0.0851[0.0684 ; 0.1044] \quad 0.2 \%$ $0.1284[0.1119 ; 0.1464] \quad 0.2 \%$ $0.1639[0.1242 ; 0.2104] \quad 0.2 \%$ $0.2102[0.1493 ; 0.2823] \quad 0.2 \%$ $0.0643[0.0467 ; 0.0859] \quad 0.2 \%$ $0.2500[0.2091 ; 0.2945] \quad 0.2 \%$ $0.1002[0.0865 ; 0.1152] \quad 0.2 \%$ $0.1188[0.0903 ; 0.1525] \quad 0.2 \%$ $0.0990[0.0673 ; 0.1390] \quad 0.2 \%$ $0.0462[0.0389 ; 0.0543] \quad 0.2 \%$ $0.2782[0.2489 ; 0.3089] \quad 0.2 \%$ $0.1218[0.0941 ; 0.1563] \quad 2.5 \%$

$0.1172[0.1005 ; 0.1356] \quad 0.2 \%$ $0.1172[0.1011 ; 0.1355] \quad 0.2 \%$

Fig. 3 (Continued).

their husbands or family members [14, 37, 38]. Violence is harmful to one's mental health. Mothers who are abused experience feelings of helplessness and despair, as well being at high risk to commit suicide. Unexpectedly, in our meta-analysis, an infant's gender is not related to postpartum depression. Although female infant sex is favorably linked to PPD, according to research conducted in Asia (China, India), Africa (Nigeria), and Turkey, with qualitative research suggesting a role for male gender preference 


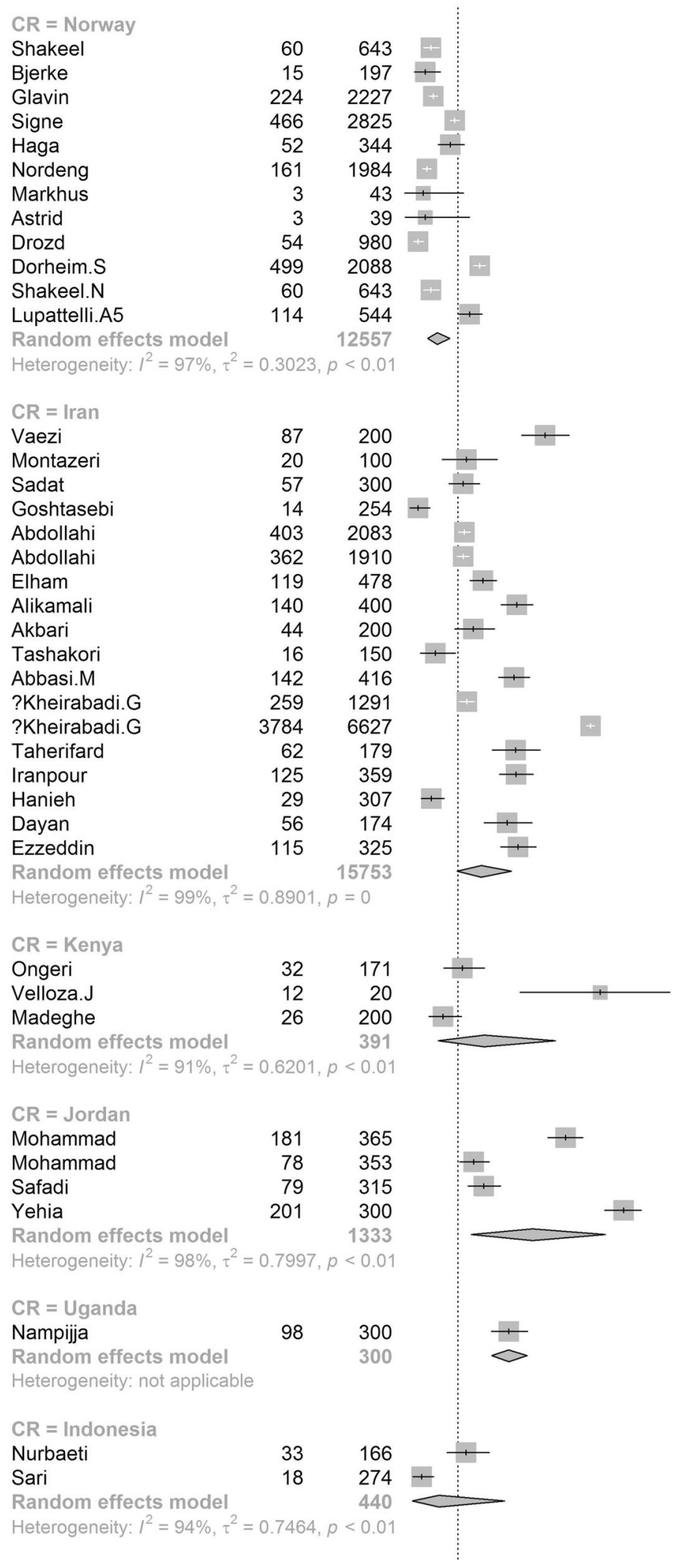

$0.0933[0.0720 \cdot 0.1185] \quad 0.2 \%$

$0.0761[0.0432 ; 0.1225] \quad 0.2 \%$

$0.1006[0.0884 ; 0.1138] \quad 0.2 \%$

$0.1650[0.1514 ; 0.1792] \quad 0.2 \%$

$0.1512[0.1150 ; 0.1935] \quad 0.2 \%$

$0.0811[0.0695 ; 0.0940] \quad 0.2 \%$

$0.0698[0.0146 ; 0.1906] \quad 0.1 \%$

$0.0769[0.0162 ; 0.2087] \quad 0.1 \%$

$0.0551[0.0417 ; 0.0713] \quad 0.2 \%$

$0.2390[0.2208 ; 0.2579] \quad 0.2 \%$

$0.0933[0.0720 ; 0.1185] \quad 0.2 \%$

$0.2096[0.1761 ; 0.2462] \quad 0.2 \%$

$0.1124[0.0831 ; 0.1503] \quad 2.0 \%$

$0.4350 \quad[0.3652 ; 0.5067] \quad 0.2 \%$

$0.2000[0.1267 ; 0.2918] \quad 0.2 \%$

$0.1900[0.1472 ; 0.2390] \quad 0.2 \%$

$0.0551[0.0305 ; 0.0908] \quad 0.2 \%$

$0.1935[0.1767 ; 0.2111] \quad 0.2 \%$

$0.1895[0.1722 ; 0.2078] \quad 0.2 \%$

$0.2490[0.2108 ; 0.2902] \quad 0.2 \%$

0.3500 [0.3033;0.3990] $0.2 \%$

$0.2200[0.1646 ; 0.2839] \quad 0.2 \%$

$0.1067[0.0622 ; 0.1674] \quad 0.2 \%$

0.3413 [0.2959;0.3891] $0.2 \%$

$0.2006[0.1791 ; 0.2235] \quad 0.2 \%$

$0.5710[0.5590 ; 0.5830] \quad 0.2 \%$

$0.3464[0.2770 ; 0.4210] \quad 0.2 \%$

$0.3482[0.2989 ; 0.4000] \quad 0.2 \%$

$0.0945[0.0642 ; 0.1328] \quad 0.2 \%$

$0.3218[0.2531 ; 0.3967] \quad 0.2 \%$

$0.3538[0.3019 ; 0.4085] \quad 0.2 \%$

$0.2441[0.1719 ; 0.3343] \quad 3.2 \%$

$0.1871[0.1317 ; 0.2538] \quad 0.2 \%$

$0.6000[0.3605 ; 0.8088] \quad 0.1 \%$

$0.1300[0.0867 ; 0.1847] \quad 0.2 \%$

$0.2520[0.1150 ; 0.4663] \quad 0.5 \%$

$0.4959[0.4434 ; 0.5484] \quad 0.2 \%$

$0.2210[0.1788 ; 0.2679] \quad 0.2 \%$

$0.2508[0.2039 ; 0.3025] \quad 0.2 \%$

$0.6700[0.6136 ; 0.7230] \quad 0.2 \%$

$0.3978[0.2143 ; 0.6154] \quad 0.7 \%$

$0.3267 \quad 0.2739 ; 0.3829] \quad 0.2 \%$

$0.3267[0.2760 ; 0.3818] \quad 0.2 \%$

$0.1988[0.1410 ; 0.2677] \quad 0.2 \%$

$0.0657 \quad[0.0394 ; 0.1018] \quad 0.2 \%$

$0.1176[0.0373 ; 0.3143] \quad 0.3 \%$

Fig. 3 (Continued).

[39-41]. However, recent studies indicated that several biological mechanisms could underlie our observed findings, including sexdifferential shifts in maternal reproductive and other hormones or immune activity [42-44].
There are strengths and limitations of this study to consider. It is the largest population-based study to-date, and allows for the investigation of factors which have not been previously studied in various regions. This study was a meta-analysis, so the pooled 
$\mathrm{CR}=$ Eswatini

Dlamini

Random effects model

Heterogeneity: not applicable

$\mathrm{CR}=$ Syria

Roumieh

Random effects model

Heterogeneity: not applicable

$\mathrm{CR}=$ Saudi Arabia

Nasr

Nagy

Alharbi

Alasoom.L

Modayfer.O

Alasoom

Alzahrani

Random effects model

Heterogeneity: $I^{2}=93 \%, \tau^{2}=0.2933, p<0.01$

$\mathrm{CR}=$ New Zealand

Abbott

Gao

Underwood.L

Jin

Chan

Random effects model

Heterogeneity: $I^{2}=98 \%, \tau^{2}=0.5766, p<0.01$

$\mathrm{CR}=$ Multi

Husain

Grote

Fellmeth

Random effects model

Heterogeneity: $I^{2}=97 \%, \tau^{2}=0.4890, p<0.01$

$\mathrm{CR}=$ Morocco

Alami

Random effects model

Heterogeneity: not applicable

$\mathrm{CR}=$ Portugal

Figueiredo

Figueiredo

Figueiredo

Alves

Random effects model

Heterogeneity: $I^{2}=78 \%, \tau^{2}=0.1569, p<0.01$

$\mathrm{CR}=$ Italy

Grussu

Giardinelli

Petrozzi

Spinola.O

Cena

Mauri.M

Lupattelli.A

Ferrari

Epifanio

Vismara

Vismara

Palumbo

Gremigni

Turner
$27 \quad 100$

100

149

929

396

1474

100
100

\section{9}

24

29

43

43
663
$1569, p<0.01$

108

108
91

91
260

204$$
39
$$$$
\begin{aligned}
& 39 \\
& 78 \\
& 45
\end{aligned}
$$$$
\begin{array}{r}
45 \\
107
\end{array}
$$

107
60

60
78

78
90

454

11

32

126

110

39

14

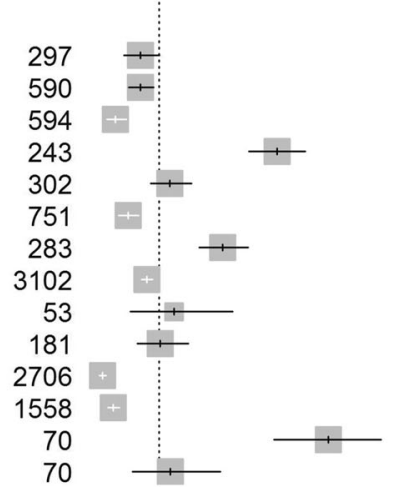

$0.4737[0.3794 ; 0.5694]$

$0.4737[0.3839 ; 0.5652] \quad 0.2 \%$

$0.2824[0.2560 ; 0.3099] \quad 0.2 \%$

$0.2824[0.2566 ; 0.3096] \quad 0.2 \%$

$0.3984[0.3130 ; 0.4887] \quad 0.2 \%$

$0.1022[0.0570 ; 0.1655] \quad 0.2 \%$

$0.3324[0.2833 ; 0.3843] \quad 0.2 \%$

$0.1778[0.1436 ; 0.2163] \quad 0.2 \%$

$0.1366[0.1095 ; 0.1675] \quad 0.2 \%$

$0.1778[0.1436 ; 0.2163] \quad 0.2 \%$

$0.1705[0.1230 ; 0.2273] \quad 0.2 \%$

$0.2008[0.1417 ; 0.2765] \quad 1.2 \%$

$0.1643[0.1450 ; 0.1851] \quad 0.2 \%$

$0.1521[0.1312 ; 0.1748] \quad 0.2 \%$

$0.0500[0.0443 ; 0.0562] \quad 0.2 \%$

$0.1519[0.0810 ; 0.2503] \quad 0.1 \%$

$0.0655[0.0371 ; 0.1057] \quad 0.2 \%$

$0.1058[0.0562 ; 0.1901] \quad 0.9 \%$

$0.3557[0.2791 ; 0.4382] \quad 0.2 \%$

$0.1098[0.0904 ; 0.1317] \quad 0.2 \%$

$0.1970[0.1589 ; 0.2396] \quad 0.2 \%$

$0.2021[0.1016 ; 0.3619] \quad 0.5 \%$

$0.2700[0.1861 ; 0.3680] \quad 0.2 \%$

$0.2700[0.1922 ; 0.3651] \quad 0.2 \%$

$0.1759[0.1094 ; 0.2610] \quad 0.2 \%$

$0.2637[0.1769 ; 0.3665] \quad 0.2 \%$

$0.1115[0.0760 ; 0.1562] \quad 0.2 \%$

0.2108 [0.1569;0.2732] $0.2 \%$

$0.1828[0.1257 ; 0.2581] \quad 0.7 \%$

$0.1313[0.0951 ; 0.1751] \quad 0.2 \%$

$0.1322[0.1059 ; 0.1622] \quad 0.2 \%$

$0.0758[0.0558 ; 0.1001] \quad 0.2 \%$

0.4403 [0.3769; 0.5052$] \quad 0.2 \%$

$0.1987[0.1552 ; 0.2482] \quad 0.2 \%$

$0.1039[0.0830 ; 0.1279] \quad 0.2 \%$

$0.3180[0.2642 ; 0.3757] \quad 0.2 \%$

$0.1464[0.1341 ; 0.1593] \quad 0.2 \%$

$0.2075[0.1084 ; 0.3411] \quad 0.1 \%$

0.1768 [0.1242;0.2403] $0.2 \%$

$0.0466[0.0389 ; 0.0552] \quad 0.2 \%$

$0.0706[0.0584 ; 0.0845] \quad 0.2 \%$

$0.5571[0.4334 ; 0.6759] \quad 0.2 \%$

0.2000 ○.1139; $0.31271 \quad 0.2 \%$

Fig. 3 (Continued).

estimates of risk factors resulted in improved accuracy compared with findings from a single study. Limitations were also identified. First, although this was the most comprehensive PPD prevalence study, there remains a significant lack of research studies from developing countries with lower-middle or low incomes. Second, since the current research focused on cross-sectional research studies, recall bias may be present. Third, the diagnostic techniques used were based on participants' self- 


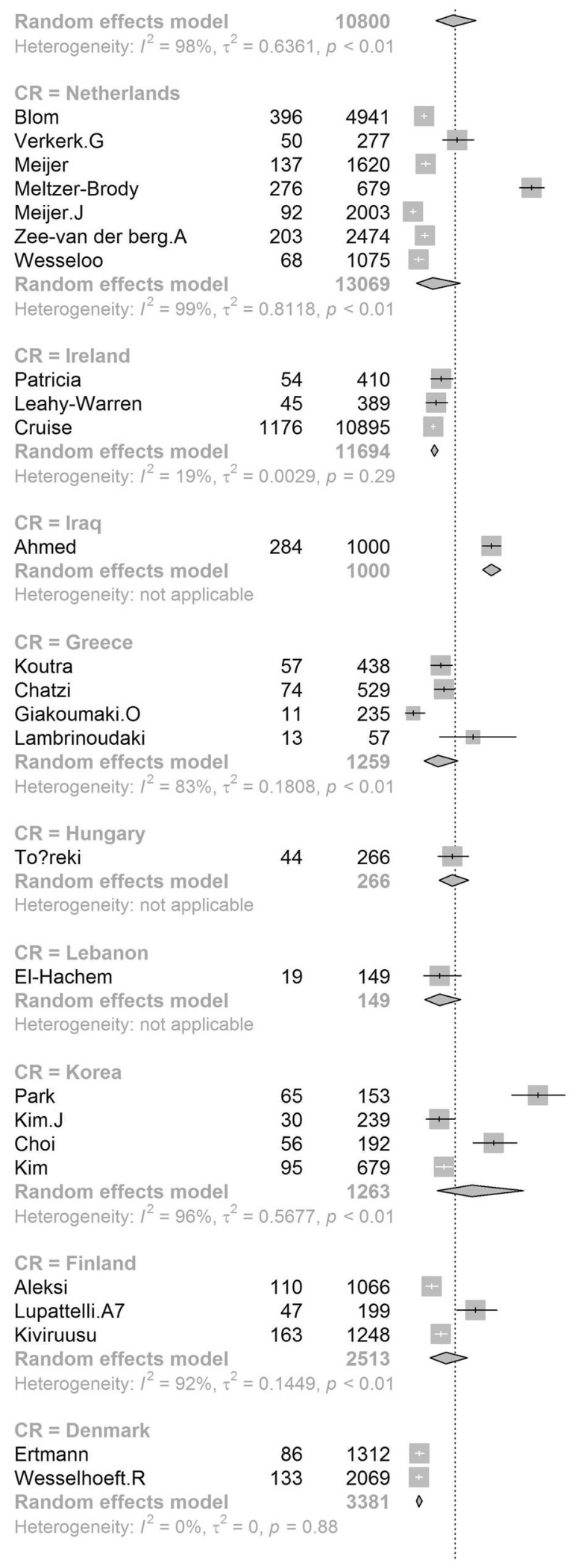

$0.0801[0.0727 ; 0.0881] \quad 0.2 \%$

$0.1805[0.1370 ; 0.2310] \quad 0.2 \%$

$0.0846[0.0715 \cdot 0.0992] \quad 0.2 \%$

$0.4065[0.3693 ; 0.4445] \quad 0.2 \%$

$0.0459[0.0372 ; 0.0560] \quad 0.2 \%$

$0.0821[0.0715 ; 0.0936] \quad 0.2 \%$

$0.0633[0.0495 ; 0.0795] \quad 0.2 \%$

$0.1069[0.0576 ; 0.1898] \quad 1.3 \%$

$0.1317[0.1005 ; 0.1683] \quad 0.2 \%$

$0.1157 \quad[0.0856 ; 0.1517] \quad 0.2 \%$

$0.1079[0.1022 ; 0.1139] \quad 0.2 \%$

$0.1114[0.1013 ; 0.1225] \quad 0.5 \%$

$0.2840[0.2562 ; 0.3131] \quad 0.2 \%$

$0.2840[0.2569 ; 0.3128] \quad 0.2 \%$

$0.1301[0.1001 ; 0.1653] \quad 0.2 \%$

$0.1399[0.1115 ; 0.1724] \quad 0.2 \%$

$0.0468[0.0236 ; 0.0822] \quad 0.1 \%$

$0.2281[0.1274 ; 0.3584] \quad 0.1 \%$

$0.1226[0.0802 ; 0.1830] \quad 0.7 \%$

$0.1654[0.1228 ; 0.2156] \quad 0.2 \%$

$0.1654[0.1254 ; 0.2150] \quad 0.2 \%$

$0.1275[0.0786 ; 0.1920] \quad 0.2 \%$

$0.1275[0.0828 ; 0.1913] \quad 0.2 \%$

$0.4248 \quad[0.3454 ; 0.5072] \quad 0.2 \%$

$0.1255[0.0863 ; 0.1743] \quad 0.2 \%$

$0.2917[0.2284 ; 0.3614] \quad 0.2 \%$

$0.1399[0.1147 ; 0.1683] \quad 0.2 \%$

$0.2250[0.1201 ; 0.3817] \quad 0.7 \%$

$0.1032[0.0856 ; 0.1230] \quad 0.2 \%$

$0.2362[0.1790 ; 0.3014] \quad 0.2 \%$

$0.1306[0.1124 ; 0.1506] \quad 0.2 \%$

$0.1462[0.0983 ; 0.2120] \quad 0.5 \%$

$0.0655[0.0528 ; 0.0803] \quad 0.2 \%$

$0.0643[0.0541 ; 0.0757] \quad 0.2 \%$

$0.0648[0.0570 ; 0.0736] \quad 0.4 \%$

Fig. 3 (Continued).

reports which can result in reporting bias. Fourth, genes and polymorphisms are reported to be associated with PPD. However, in current study, we cannot further pool estimate those data due to the limited number of study on specific genes.
Postpartum depression affected one out of every five women after they gave birth which was triggered by a variety of causes. This necessitates the attention and committed intervention of primary care providers, clinicians, health authorities, and society as a whole. 


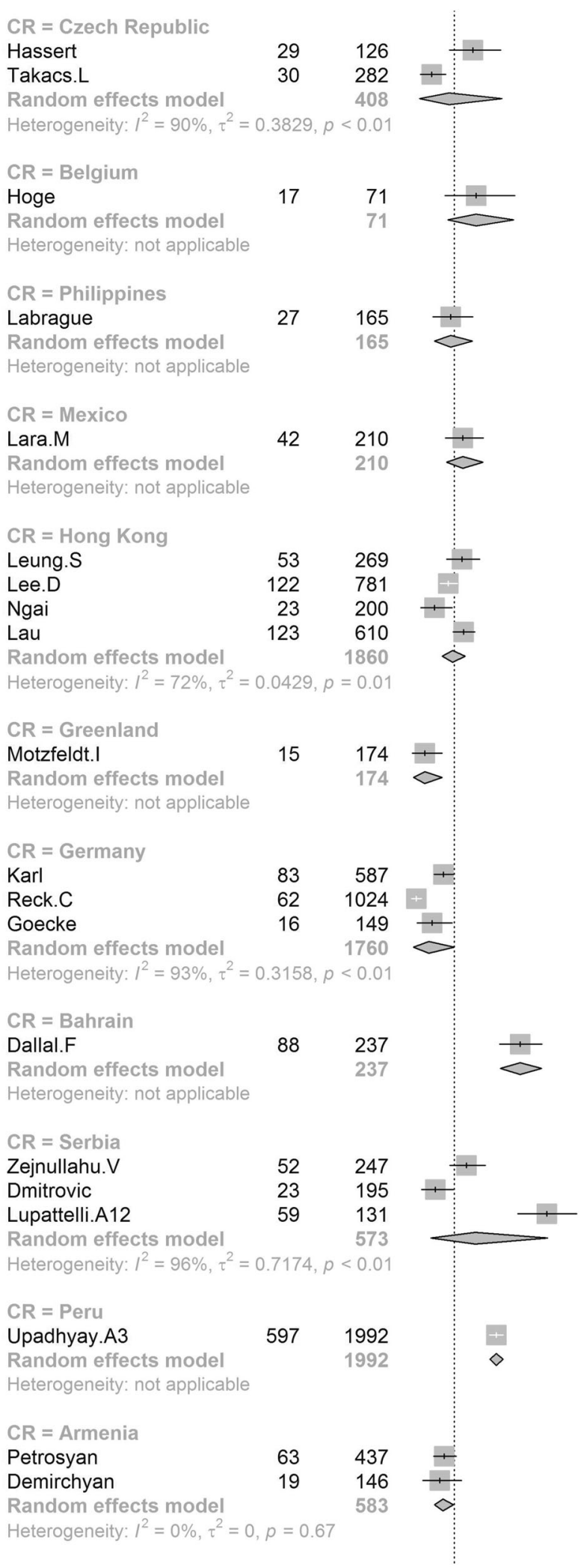

$0.2302[0.1599 ; 0.3135] \quad 0.2 \%$

0.1064 [0.0729; 0.1484$] \quad 0.2 \%$

$0.1582[0.0708 ; 0.3166] \quad 0.3 \%$

$0.2394[0.1461 ; 0.3554] \quad 0.2 \%$

$0.2394[0.1544 ; 0.3519] \quad 0.2 \%$

$0.1636[0.1107 ; 0.2291] \quad 0.2 \%$

$0.1636[0.1147 ; 0.2281] \quad 0.2 \%$

$0.2000[0.1481 ; 0.2606] \quad 0.2 \%$

$0.2000[0.1513 ; 0.2596] \quad 0.2 \%$

$0.1970[0.1512 ; 0.2497] \quad 0.2 \%$

$0.1562[0.1314 ; 0.1836] \quad 0.2 \%$

$0.1150[0.0743 ; 0.1675] \quad 0.2 \%$

$0.2016[0.1705 ; 0.2357] \quad 0.2 \%$

$0.1696[0.1377 ; 0.2070] \quad 0.7 \%$

$0.0862[0.0491 ; 0.1382] \quad 0.2 \%$

$0.0862[0.0526 ; 0.1381] \quad 0.2 \%$

$0.1414[0.1142 ; 0.1722] \quad 0.2 \%$

$0.0605[0.0467 ; 0.0769] \quad 0.2 \%$

$0.1074[0.0626 ; 0.1685] \quad 0.2 \%$

$0.0976[0.0526 ; 0.1740] \quad 0.5 \%$

$0.3713[0.3096 ; 0.4362] \quad 0.2 \%$

$0.3713[0.3121 ; 0.4346] \quad 0.2 \%$

$0.2105[0.1614 ; 0.2667] \quad 0.2 \%$

$0.1179[0.0763 ; 0.1717] \quad 0.2 \%$

$0.4504[0.3634 ; 0.5397] \quad 0.2 \%$

$0.2366[0.1041 ; 0.4527] \quad 0.5 \%$

$0.2997[0.2796 ; 0.3204] \quad 0.2 \%$

$0.2997[0.2800 ; 0.3202] \quad 0.2 \%$

$0.1442[0.1126 ; 0.1806] \quad 0.2 \%$

$0.1301[0.0802 ; 0.1957] \quad 0.2 \%$

$0.1408[0.1148 ; 0.1714] \quad 0.3 \%$

Fig. 3 (Continued). 


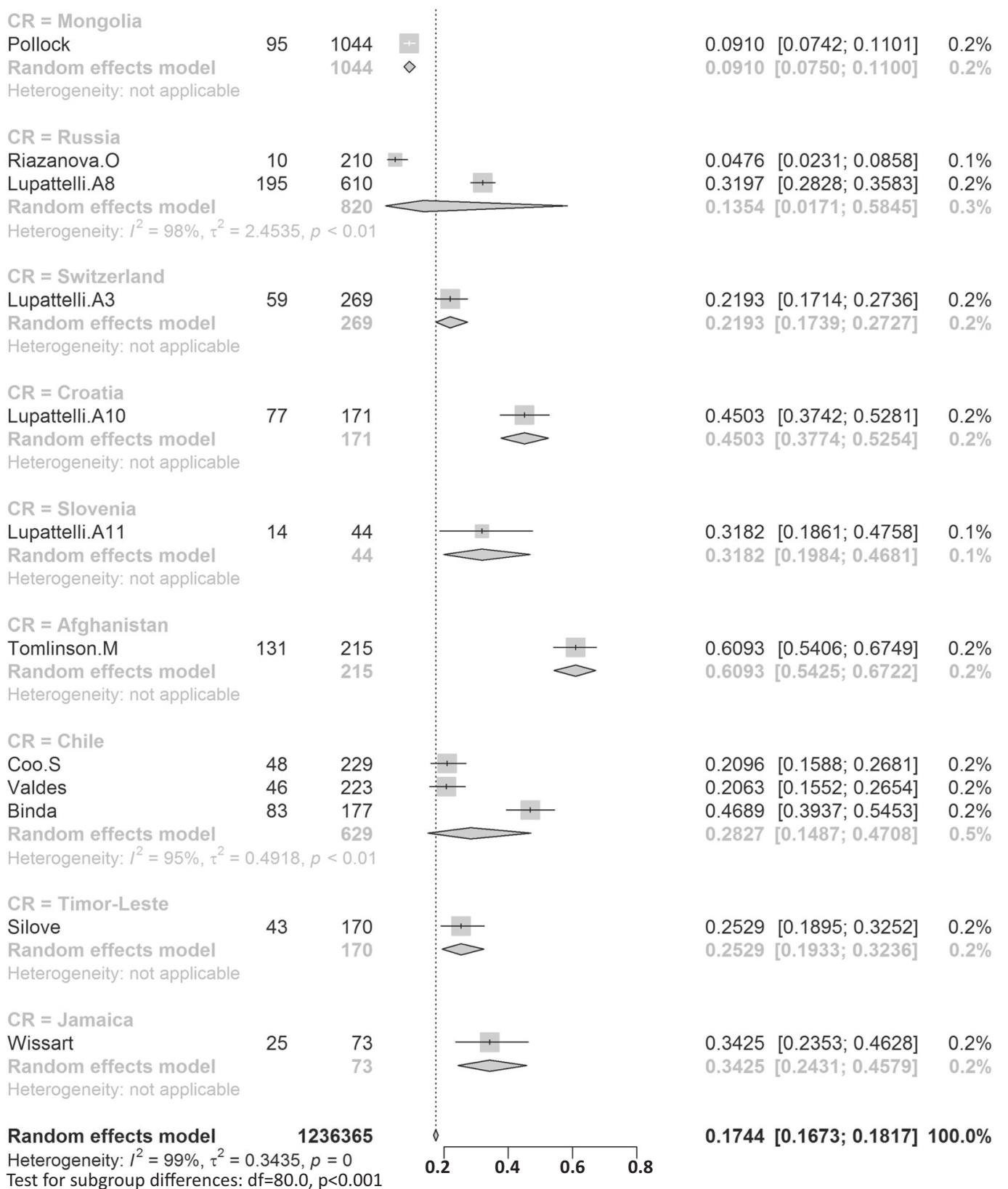

Fig. 3 (Continued).

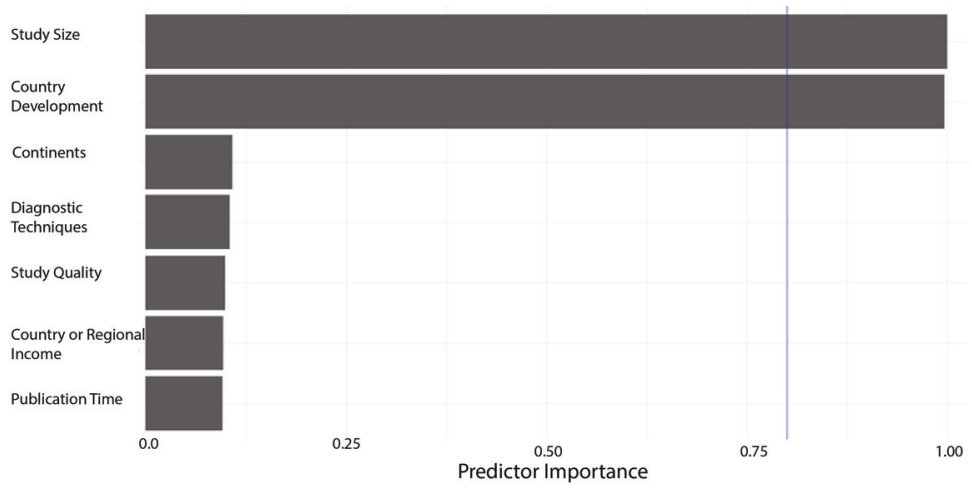

Fig. 4 Multi-variable meta-regression for postpartum depression prevalence. (Multi-variable meta-regression was performed in order to find out factors with the highest predictor importance). 
Table 2. Pooled estimates of risk factors for PPD.

\begin{tabular}{|c|c|c|c|c|c|c|}
\hline & Studies & PPD & Participants & Prevalence $(95 \% \mathrm{Cl})$ & $P$ value & $I^{2}$ \\
\hline Age (in years) & & & & & 0.52 & \\
\hline$<20$ & 54 & 3412 & 24310 & $23.34(18.58-28.89)$ & & $97.60 \%$ \\
\hline Alcohol use & & & & & 0.02 & \\
\hline Yes & 18 & 1387 & 10311 & $20.97(15.73-27.39)$ & & $92.20 \%$ \\
\hline No & 17 & 11000 & 80111 & $14.49(12.52-16.72)$ & & $91.60 \%$ \\
\hline Yes & 49 & 7747 & 62410 & 16.51 (13.64-19.84) & & $98.30 \%$ \\
\hline No & 50 & 1225 & 5568 & $25.03(20.99-29.54)$ & & $89.40 \%$ \\
\hline Parity & & & & & 0.92 & \\
\hline Primiparous & 120 & 21666 & 834265 & $17.39(13.44-22.19)$ & & $99.70 \%$ \\
\hline Multiparous & 120 & 15834 & 166938 & $17.63(15.48-20.00)$ & & $98.40 \%$ \\
\hline Paid employment & 117 & 6802 & 48324 & $18.29(15.80-21.08)$ & & $97.30 \%$ \\
\hline Unemployment & 118 & 7331 & 37230 & $21.08(19.05-23.25)$ & & $95.10 \%$ \\
\hline Ethnicity & & & & & 0.27 & \\
\hline Indigenous & 41 & 4114 & 38404 & $14.76(12.19-17.76)$ & & $97.50 \%$ \\
\hline Nonindigenous or immigrant & 41 & 4783 & 38948 & $17.06(14.22-20.35)$ & & $96.90 \%$ \\
\hline Family type & & & & & 0.82 & \\
\hline Nuclear & 34 & 2378 & 11362 & $20.66(17.95-23.67)$ & & $91.50 \%$ \\
\hline Extend & 34 & 2763 & 12870 & $21.15(18.30-24.31)$ & & $92.70 \%$ \\
\hline Financial problems & & & & & $<0.01$ & \\
\hline pre- or post-term & 42 & 3169 & 21341 & $22.04(18.14-26.52)$ & & $93.10 \%$ \\
\hline Infant death & & & & & 0.01 & \\
\hline Yes & 17 & 479 & 1294 & $43.44(25.89-62.80)$ & & $94.50 \%$ \\
\hline No & 15 & 1493 & 18042 & $18.50(11.53-28.35)$ & & $98.90 \%$ \\
\hline Infant illness & & & & & $<0.01$ & \\
\hline Yes & 41 & 2597 & 11180 & $29.00(21.78-37.46)$ & & $97.80 \%$ \\
\hline No & 40 & 5793 & 44536 & 17.95 (14.74-21.67) & & $98.10 \%$ \\
\hline Infant weight & & & & & 0.14 & \\
\hline Normal & 29 & 2490 & 18083 & $17.41(14.00-21.45)$ & & $96.90 \%$ \\
\hline Abnormal & 29 & 629 & 3582 & $23.55(16.75-32.05)$ & & $94.30 \%$ \\
\hline Infant sex & & & & & 0.13 & \\
\hline Male & 78 & 10252 & 72227 & $17.97(15.62-20.58)$ & & $97.40 \%$ \\
\hline Female & 77 & 9760 & 67494 & $20.77(18.20-23.60)$ & & $97.20 \%$ \\
\hline Life stress & & & & & $<0.01$ & \\
\hline Yes & 35 & 3735 & 23151 & $28.81(23.49-34.78)$ & & $96.70 \%$ \\
\hline No & 35 & 2538 & 20435 & $14.53(11.84-17.70)$ & & $96.10 \%$ \\
\hline Delivery Location & & & & & 0.49 & \\
\hline Home & 11 & 316 & 5984 & $14.88(6.93-29.10)$ & & $96.90 \%$ \\
\hline
\end{tabular}




\section{Table 2 continued}

\begin{tabular}{|c|c|c|c|c|c|c|}
\hline & Studies & PPD & Participants & Prevalence $(95 \% \mathrm{Cl})$ & $P$ value & $I^{2}$ \\
\hline Health facility & 11 & 969 & 15285 & $11.08(7.29-16.50)$ & & $97.40 \%$ \\
\hline Marital status & & & & & $<0.01$ & \\
\hline Married or cohabiting & 91 & 22284 & 168779 & $16.37(14.55-18.37)$ & & $98.50 \%$ \\
\hline Single (unmarried, widowed or divorced) & 91 & 5247 & 26763 & $28.14(24.96-31.55)$ & & $94.40 \%$ \\
\hline Maternal health problems (perinatal period) & & & & & 0.01 & \\
\hline Yes & 68 & 7970 & 77815 & $23.97(19.40-29.23)$ & & $98.30 \%$ \\
\hline Mode of delivery & & & & & 0.4 & \\
\hline Spontaneous & 125 & 25499 & 972401 & $18.31(14.34-23.08)$ & & $99.70 \%$ \\
\hline Instrument or CS & 126 & 19053 & 555861 & $21.01(16.83-25.90)$ & & $99.60 \%$ \\
\hline Number of children & & & & & 0.68 & \\
\hline 1 or less & 20 & 645 & 3355 & $17.74(13.18-23.45)$ & & $92.80 \%$ \\
\hline Partnership & & & & & $<0.01$ & \\
\hline Intimate or satisfied & 42 & 4035 & 23404 & $17.11(14.54-20.04)$ & & $96.50 \%$ \\
\hline Unsatisfied & 42 & 1569 & 4921 & $39.96(33.33-46.98)$ & & $94.00 \%$ \\
\hline Pregnancy plan & & & & & $<0.01$ & \\
\hline Planned & 81 & 5840 & 45033 & $17.36(14.91-20.12)$ & & $97.40 \%$ \\
\hline Unplanned & 81 & 4237 & 22925 & $28.12(24.18-32.43)$ & & $96.70 \%$ \\
\hline Religion & & & & & 0.77 & \\
\hline Yes & 9 & 816 & 14470 & $15.11(6.25-32.23)$ & & $99.20 \%$ \\
\hline No & 9 & 489 & 3448 & $17.47(10.65-27.33)$ & & $96.00 \%$ \\
\hline Residence & & & & & 0.73 & \\
\hline Yes & 36 & 1238 & 6948 & $25.17(20.84-30.07)$ & & $88.80 \%$ \\
\hline No & 35 & 13314 & 97611 & $15.74(13.93-17.73)$ & & $95.70 \%$ \\
\hline Social support & & & & & $<0.01$ & \\
\hline Yes & 55 & 4467 & 29888 & $15.15(12.93-17.68)$ & & $96.60 \%$ \\
\hline No & 55 & 2741 & 10078 & $32.03(27.42-37.02)$ & & $95.00 \%$ \\
\hline Violence & & & & & $<0.01$ & \\
\hline Yes & 37 & 2210 & 6987 & $40.40(34.11-47.02)$ & & $95.00 \%$ \\
\hline No & 37 & 14631 & 111554 & $15.65(12.88-18.89)$ & & $98.60 \%$ \\
\hline
\end{tabular}

$\mathrm{CS}=$ Cesarean section

\section{REFERENCES}

1. Crotty F, Sheehan J. Prevalence and detection of postnatal depression in an Irish community sample. Ir J Psychol Med. 2004;21:117-21.

2. Cooper PJ, Murray L, Wilson A, Romaniuk H. Controlled trial of the short- and long-term effect of psychological treatment of post-partum depression. I. Impact on maternal mood. Br J Psychiatry. 2003;182:412-9.

3. Cox JL, Murray D, Chapman G. A controlled study of the onset, duration and prevalence of postnatal depression. Br J Psychiatry. 1993;163:27-31.

4. Pearlstein T, Howard M, Salisbury A, Zlotnick C. Postpartum depression. Am J Obstet Gynecol. 2009;200:357-64.

5. Lovestone S, Kumar R. Postnatal psychiatric illness: the impact on partners. Br J Psychiatry. 1993;163:210-6.
6. Murray L, Fiori-Cowley A, Hooper R, Cooper P. The impact of postnatal depression and associated adversity on early mother-infant interactions and later infant outcome. Child Dev. 1996;67:2512-26.

7. Robertson E, Grace S, Wallington T, Stewart DE. Antenatal risk factors for postpartum depression: a synthesis of recent literature. Gen Hosp Psychiatry. 2004;26:289-95.

8. Faisal-Cury A, Menezes PR, d'Oliveira AF, Schraiber LB, Lopes CS. Temporal relationship between intimate partner violence and postpartum depression in a sample of low income women. Matern Child Health J. 2013;17:1297-303.

9. Halbreich U, Karkun S. Cross-cultural and social diversity of prevalence of postpartum depression and depressive symptoms. J Affect Disord. 2006;91:97-111.

10. O'Hara MW, Swain AM. Rates and risk of postpartum depression-a metaanalysis. Int Rev Psychiatry. 1996;8:37-54. 
11. Shorey S, Chee CYI, Ng ED, Chan YH, Tam WWS, Chong YS. Prevalence and incidence of postpartum depression among healthy mothers: A systematic review and meta-analysis. J Psychiatr Res. 2018;104:235-48.

12. Fisher J, Cabral de Mello M, Patel V, Rahman A, Tran T, Holton S, et al. Prevalence and determinants of common perinatal mental disorders in women in low- and lowermiddle-income countries: a systematic review. Bull World Health Organ. 2012;90:139G-149G.

13. Hahn-Holbrook J, Cornwell-Hinrichs T, Anaya I. Economic and health predictors of national postpartum depression prevalence: a systematic review, meta-analysis, and meta-regression of 291 studies from 56 countries. Front Psychiatry. 2017;8:248.

14. Upadhyay RP, Chowdhury R, Aslyeh S, Sarkar K, Singh SK, Sinha B, et al. Postpartum depression in India: a systematic review and meta-analysis. Bull World Health Organ. 2017;95:706-717C

15. Ozcan NK, Boyacioglu NE, Dinc H. Postpartum depression prevalence and risk factors in Turkey: a systematic review and meta-analysis. Arch Psychiatr Nurs. 2017;31:420-8.

16. Zeleke TA, Getinet W, Tadesse Tessema Z, Gebeyehu K. Prevalence and associated factors of post-partum depression in Ethiopia. A systematic review and meta-analysis. PLoS One. 2021;16:e0247005.

17. Norhayati MN, Hazlina NH, Asrenee AR, Emilin WM. Magnitude and risk factors for postpartum symptoms: a literature review. J Affect Disord. 2015;175:34-52.

18. Villegas L, McKay K, Dennis CL, Ross LE. Postpartum depression among rural women from developed and developing countries: a systematic review. J Rural Health. 2011;27:278-88.

19. Klainin P, Arthur DG. Postpartum depression in Asian cultures: a literature review. Int J Nurs Stud. 2009;46:1355-73.

20. Affonso DD, De AK, Horowitz JA, Mayberry $\sqcup$. An international study exploring levels of postpartum depressive symptomatology. J Psychosom Res. 2000;49:207-16.

21. Bener A, Gerber LM, Sheikh J. Prevalence of psychiatric disorders and associated risk factors in women during their postpartum period: a major public health problem and global comparison. Int J Women's Health. 2012;4:191-200.

22. Kheirabadi GR, Maracy MR, Barekatain M, Salehi M, Sadri GH, Kelishadi M, et al. Risk factors of postpartum depression in rural areas of Isfahan Province, Iran. Arch Iran Med. 2009;12:461-7.

23. Green K, Broome H, Mirabella J. Postnatal depression among mothers in the United Arab Emirates: socio-cultural and physical factors. Psychol Health Med. 2006;11:425-31.

24. Rizk DE, Nasser M, Thomas L, Ezimokhai M. Women's perceptions and experiences of childbirth in United Arab Emirates. J Perinat Med. 2001;29:298-307.

25. Balaha, $\mathrm{MH}$, Obstetric and Psychiatric Outcomes in a Sample of Saudi Teen-Aged Mothers 8, 2009. : p. 285-90.

26. Kim-Godwin YS. Postpartum beliefs and practices among non-Western cultures. MCN Am J Matern Child Nurs. 2003;28:74-8. quiz 79-80

27. Hamdan A, Tamim H. Psychosocial risk and protective factors for postpartum depression in the United Arab Emirates. Arch Women's Ment Health. 2011;14:125-33.

28. Chaaya M, Campbell OM, El Kak F, Shaar D, Harb H, Kaddour A. Postpartum depression: prevalence and determinants in Lebanon. Arch Women's Ment Health. 2002;5:65-72.

29. Dibaba Y, Fantahun M, Hindin MJ. The association of unwanted pregnancy and social support with depressive symptoms in pregnancy: evidence from rural Southwestern Ethiopia. BMC Pregnancy Childbirth. 2013;13:135.

30. Monti F, Agostini F, Fagandini P, La Sala GB, Blickstein I. Depressive symptoms during late pregnancy and early parenthood following assisted reproductive technology. Fertil Steril. 2009;91:851-7.

31. Dias CC, Figueiredo B. Breastfeeding and depression: a systematic review of the literature. J Affect Disord. 2015;171:142-54.

32. Henshaw EJ, Fried R, Siskind E, Newhouse L, Cooper M. Breastfeeding self-efficacy, mood, and breastfeeding outcomes among primiparous women. J Hum Lact. 2015;31:511-8.

33. Baker L, Cross S, Greaver L, Wei G, Lewis R, Healthy Start C. Prevalence of postpartum depression in a native American population. Matern Child Health J. 2005;9:21-5.

34. Parsons CE, Young KS, Rochat TJ, Kringelbach ML, Stein A. Postnatal depression and its effects on child development: a review of evidence from low- and middleincome countries. Br Med Bull. 2012;101:57-79.

35. Bell AF, Carter CS, Davis JM, Golding J, Adejumo O, Pyra M, et al. Childbirth and symptoms of postpartum depression and anxiety: a prospective birth cohort study. Arch Women's Ment Health. 2016;19:219-27.

36. Gelaye B, Rondon MB, Araya R, Williams MA. Epidemiology of maternal depression, risk factors, and child outcomes in low-income and middle-income countries. Lancet Psychiatry. 2016;3:973-82.

37. Patel HL, Ganjiwale JD, Nimbalkar AS, Vani SN, Vasa R, Nimbalkar SM. Characteristics of postpartum depression in Anand District, Gujarat, India. J Trop Pediatr. 2015;61:364-9.
38. Ongeri L, Wanga V, Otieno $P$, Mbui J, Juma E, Stoep AV, et al. Demographic, psychosocial and clinical factors associated with postpartum depression in Kenyan women. BMC Psychiatry. 2018;18:318

39. Adewuya AO, Fatoye FO, Ola BA, ljaodola OR, Ibigbami SM. Sociodemographic and obstetric risk factors for postpartum depressive symptoms in Nigerian women. J Psychiatr Pr. 2005;11:353-8.

40. Ekuklu G, Tokuc B, Eskiocak M, Berberoglu U, Saltik A. Prevalence of postpartum depression in Edirne, Turkey, and related factors. J Reprod Med. 2004;49:908-14.

41. Patel V, Rodrigues M, DeSouza N. Gender, poverty, and postnatal depression: a study of mothers in Goa, India. Am J Psychiatry. 2002;159:43-7.

42. Galea LA, Wide JK, Barr AM. Estradiol alleviates depressive-like symptoms in a novel animal model of post-partum depression. Behav Brain Res. 2001;122:1-9.

43. Green AD, Barr AM, Galea LA. Role of estradiol withdrawal in 'anhedonic' sucrose consumption: a model of postpartum depression. Physiol Behav. 2009;97:259-65.

44. Schiller CE, O'Hara MW, Rubinow DR, Johnson AK. Estradiol modulates anhedonia and behavioral despair in rats and negative affect in a subgroup of women at high risk for postpartum depression. Physiol Behav. 2013;119:137-44.

\section{ACKNOWLEDGEMENTS}

We thank Pengfei Li and Ling Wang from Erasmus University Rotterdam provided English revision for the manuscript and Prof. Han Luo from Sichuan University for providing us technical assistance for the revision. This research is supported by the National Key R\&D Program of China grant (2018YFC1314600) to ZL; Grant of Science and Technology from Sichuan Province (2020YJ0237) to ZL and (2020YFS0259) to XF; The 1.3.5 project for disciplines of excellence, West China Hospital, Sichuan University to ZL (ZYJC18025); The National Natural Science Foundation of China to BY (72174152).

\section{AUTHOR CONTRIBUTIONS}

$\mathrm{JL}, \mathrm{ZW}, \mathrm{HS}, \mathrm{ZC}$, and SL completed the study, acquisition, and analysis of data. $\mathrm{YL}, \mathrm{XX}, \mathrm{ZL}$, $Z L$, WZ, and BY discussed data; conceptualized the research project, revised the manuscript and provided technical assistance. ZW and $\mathrm{JL}$ drafted the manuscript. All authors have read the manuscript and provided feedback. ZW, JL, HS, and ZC shared the co-first author.

\section{COMPETING INTERESTS}

The authors declare no competing interests.

\section{ADDITIONAL INFORMATION}

Supplementary information The online version contains supplementary material available at https://doi.org/10.1038/s41398-021-01663-6.

Correspondence and requests for materials should be addressed to Zhongchun Liu, Zhihui Li or Bing Xiang Yang.

Reprints and permission information is available at http://www.nature.com/ reprints

Publisher's note Springer Nature remains neutral with regard to jurisdictional claims in published maps and institutional affiliations.

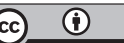

Open Access This article is licensed under a Creative Commons Attribution 4.0 International License, which permits use, sharing, adaptation, distribution and reproduction in any medium or format, as long as you give appropriate credit to the original author(s) and the source, provide a link to the Creative Commons license, and indicate if changes were made. The images or other third party material in this article are included in the article's Creative Commons license, unless indicated otherwise in a credit line to the material. If material is not included in the article's Creative Commons license and your intended use is not permitted by statutory regulation or exceeds the permitted use, you will need to obtain permission directly from the copyright holder. To view a copy of this license, visit http://creativecommons. org/licenses/by/4.0/.

(c) The Author(s) 2021, corrected publication 2021 